\title{
Fullerenes and PAHs: A Novel Model Explains their Formation via Sequential Cycloaddition Reactions Involving $C_{2}$ Dimers
}

\author{
Sylvain L. Smadja \\ sl.smadja@innido.com \\ 10364 Almayo Ave., Suite 304 \\ Los Angeles, CA 90064
}

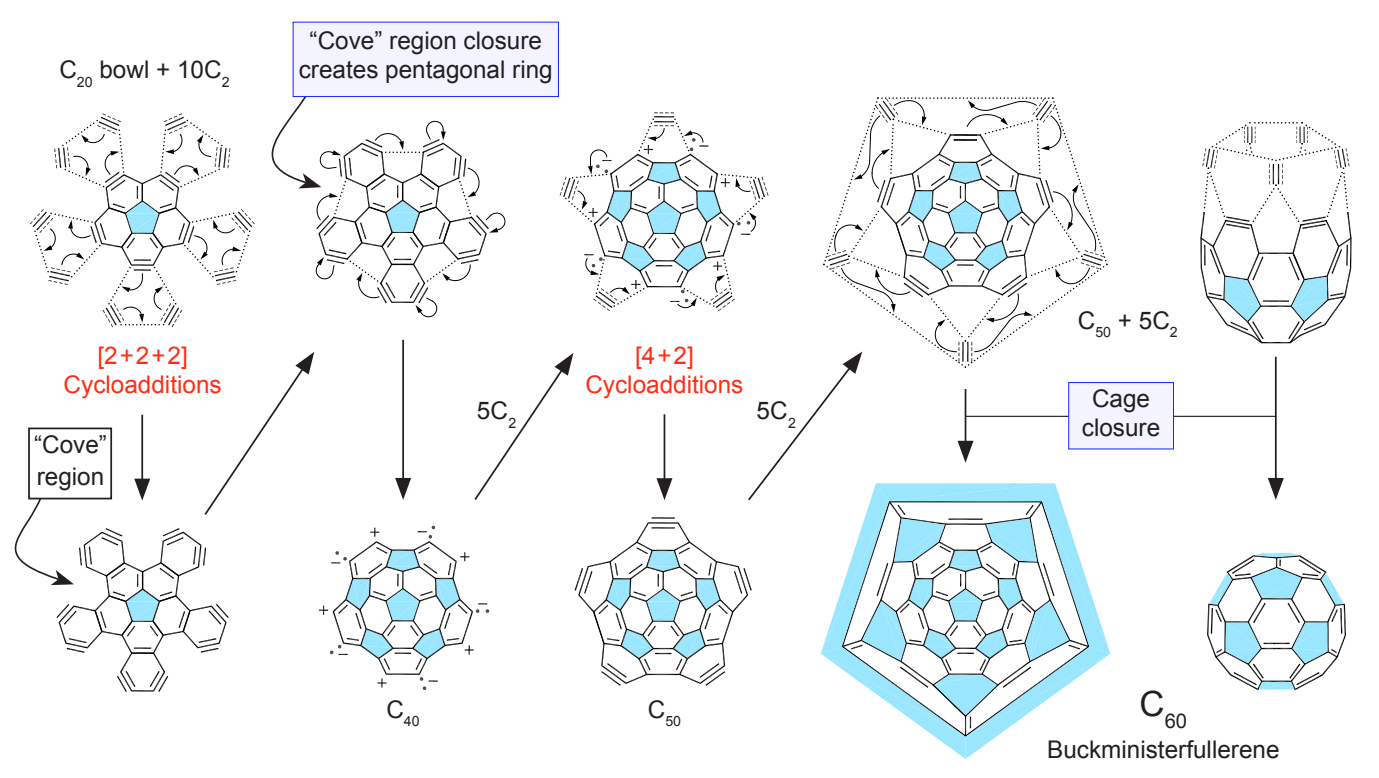

ABSTRACT: Based on a new understanding of the nature of the bonding in the $\mathrm{C}_{2}$ dimer, a novel bottom-up model is offered that can explain the growth processes of fullerenes and polycyclic aromatic hydrocarbons (PAHs). It is shown how growth sequences involving $\mathrm{C}_{2}$ dimers, that take place in carbon vapor, combustion systems, and the ISM, could give rise to a variety of bare carbon clusters. Among the bare carbon clusters thus formed, some could lead to fullerenes, while others, after hydrogenation, could lead to PAHs. We propose that the formation of hexagonal rings present in these bare carbon clusters are the result of $[2+2+2]$ and [4+2] cycloaddition reactions that involve $\mathrm{C}_{2}$ dimers. In the $\mathrm{C}_{60}$ and $\mathrm{C}_{70}$ fullerenes, each of the twelve pentagons is surrounded by five hexagons and thereby "isolated" from each other. To explain why, we suggest that in bowl-shaped clusters the pentagons can form as the consequence of closures of "cove regions" that exist between hexagonal rings, and that they can also form during cage-closure, which results in the creation of six "isolated" pentagonal rings, and five hexagonal rings. The proposed growth mechanisms can account for the formation of fullerene isomers without the need to invoke the widely used Stone-Wales rearrangement. Considering processes that take place in combustion systems, it is proposed that soot particle inception can result from oligomerization of the bare carbon clusters that originated from cycloadditions involving $\mathrm{C}_{2}$ dimers. In future work, the insights offered in this article could provide a better understanding of nanotube growth, with or without defects.

\section{Introduction}

In 1985, Kroto et al ${ }^{[1]}$ discovered that, among the gas-phase carbon ions that were produced by laser vaporization of graphite, $\mathrm{C}_{60}{ }^{+}$was remarkably stable. They proposed that its stability resulted from it being a cage-like fused-ring structure in the shape of a truncated icosahedron, a polygon with 60 vertices that resembles a soccer ball consisting of 20 hexagons and 12 pentagons with each pentagon surrounded by five hexagons. They dubbed this $\mathrm{C}_{60}{ }^{+}$ion the "buckminsterfullerene" after the architect, Buckminster Fuller, who was famous for geodesic constructions that involved hexagons and pentagons. This postulated structure was confirmed in 1990 by Krätschmer and Huffman, ${ }^{[2]}$ who were able to produce macroscopic quantities of $\mathrm{C}_{60}$ and other larger fullerenes by creating arcs between two graphite rods in a helium atmosphere. Those early experiments opened up a new field of carbon chemistry and became the definitive starting point of the carbon nanotechnology era. To explain how these carboncage nanomaterials could be produced, various "bottom-up" models ${ }^{[3]}$ as well as "top-down" models ${ }^{[4]}$ have been proposed. However, as stated by Dunk et al. ${ }^{\left[{ }^{[d]}\right]}$ and by Zhang et al., ${ }^{[4 d]}$ the mechanism of their formation "remains a mystery."

To get a better understanding of the growth mechanism of fullerenes produced during reactions that involve laser ablation or arc-graphite discharge, several teams performed a series of experiments using either hydrogenation ${ }^{[5]}$ or chlorination ${ }^{[6]}$ processes with the goal of trapping carbon cluster intermediates that are produced along the routes to $\mathrm{C}_{60}$ and $\mathrm{C}_{70}$. These experiments showed that many of those trapped intermediates exhibit the carbon skeleton of polycyclic aromatic hydrocarbons (PAHs). This implies that these clusters, which when hydrogenated would yield PAHs, and when chlorinated would yield chloro-PAHs, share the same growth mechanisms as the clusters that would yield fullerenes. 
What could be the nature of these growth mechanisms that are responsible for the formation of both fullerenes and PAHs?

We propose that during processes involving laser vaporization and arc-discharge of graphite, $\mathrm{C}_{2}$ dimers play a key role as growth species in creating bare carbon clusters as the result of [4+2] and [2+2+2] cycloadditions. Among these carbon clusters, some could form cagedstructures, others, if hydrogenated, could produce PAHs. Note that the idea of $\mathrm{C}_{2}$ dimers playing an important role in growth of fullerenes was previously suggested by several teams. ${ }^{[3 \mathrm{~b}-\mathrm{f}, 5 \mathrm{a}, 7 \mathrm{a}-\mathrm{c}]}$ However, the model being proposed here departs from previous models by how the hexagonal and pentagonal rings are created during growth processes.

The suggested role of $\mathrm{C}_{2}$ dimers can be substantiated by several experimental studies during which the presence of $\mathrm{C}_{2}$ dimers was confirmed. For example: 1) Skell and Plonkas ${ }^{[8]}$ concluded that vapor from a $16 \mathrm{~V}$ carbon arc contained $\sim 28 \mathrm{wt} \%$ diatomic carbon $\mathrm{C}_{2} ; 2$ ) the Swan bands of $\mathrm{C}_{2}$ molecules were observed by optical emission spectroscopy during the formation of soot that contains fullerenes such as $\mathrm{C}_{60}$ and $\mathrm{C}_{70}{ }^{\left[{ }^{[9]}\right.}$ 3) photoemission spectroscopy of the regenerative soot indicated $C_{2}$ to be an important constituent of carbonaceous plasma that may lead to fullerene formation, ${ }^{[10]}$ and; 4) an experimental investigation by Labazan et al. ${ }^{[11]}$ shows $\mathrm{C}_{2}$ dimers being formed as the result of laser ablation of graphite targets.

We further propose that $\mathrm{C}_{2}$ dimers may also play the key role as the growth species in creating fullerenes and PAHs in combustion systems and the interstellar medium (ISM). Regarding this proposed role, let us note that $\mathrm{C}_{2}$ dimers have been detected as early as 1857 in candle flames. ${ }^{[12]}$ Since then, numerous studies reported the detection of $\mathrm{C}_{2}$ in all carboncontaining flames ${ }^{[13]}$ such as sooty ethylene flames ${ }^{[14]}$ and oxyacetylene flames. ${ }^{[15]}$ In the ISM, the $\mathrm{C}_{2}$ dimer is has been identified in many environments including comets, ${ }^{[16]}$ interstellar clouds ${ }^{[17]}$ and the Sun. ${ }^{[18]}$

This article is organized as follows: Section 2 is a discussion of how to best describe the chemical bonding of $\mathrm{C}_{2}$, which is a topic that is still a subject of an intense debate among specialists. Section 3 is a discussion about the role (insertion vs. addition) that the $\mathrm{C}_{2}$ dimer could play during growth processes. Section 4 is a detailed review of experimental studies related to the trapping processes that produced, during laser ablation of graphite and carbon-arc reactions, fullerenes and hydrogenated or chlorinated carbon clusters that exhibit the skeletons of PAHs. From Section 5 through Section 8 we propose a series of detailed growth routes that, during laser ablation of graphite or carbon arc discharge processes, could be responsible for the formation of $I_{\mathrm{h}}-\mathrm{C}_{60}, D_{5 \mathrm{~h}}-\mathrm{C}_{70}$, isomers of $I_{\mathrm{h}}-\mathrm{C}_{60}$, and $D_{5 \mathrm{~d}}-\mathrm{C}_{50}$. In Section 9 we propose a series of growth sequences that could produce, during laser ablation of graphite or carbon arc discharge processes, numerous bare carbon clusters which, if hydrogenated, would yield a variety of PAHs. In Section 10 we propose that $\mathrm{C}_{2}$ dimers, instead of acetylene molecules, play the key role in the formation of fullerenes and PAHs in sooting combustion systems and in the ISM. Concluding remarks are offered in Section 11.

\section{Chemical Bonding in the $C_{2}$ Dimer}

The nature of the bonding in $\mathrm{C}_{2}$ in its ground state has been the subject of debate among specialists working in the field of theoretical chemistry and numerous models have been proposed. In 1974, to describe the bonding in $\mathrm{C}_{2}$, Levine ${ }^{[19]}$ applied the simplified molecular orbital (MO) model and concluded that the bonding consists of two $\pi$ bonds and no $\sigma$ bonds. Within this model, the calculated bond order is 2, thus it is depicted as a double-bonded molecule shown as structure $\mathbf{1}$ in Figure 1. Starting in 2011, theoretical computational studies by Shaik et al. ${ }^{[20]}$ led them to

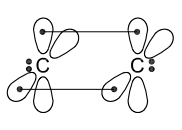

1

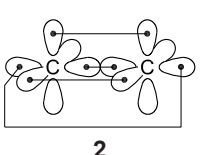

2

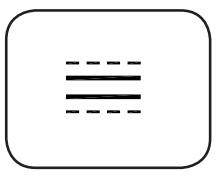

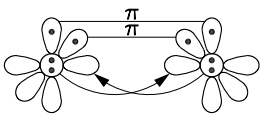

3
Proposed topological depiction of the bonding in $\mathrm{C}_{2}$ that is used in this article.

Figure 1. Bonding models of the carbon dimer $\left(C_{2}\right)$ in its ground state: 1 : The doubly-bonded structure based on a MO study by Levine ${ }^{[19]}$ that consists of two $\pi$ bonds; 2: the quadruply-bonded structure based on studies by Shaik et al. ${ }^{[20-21]}$ that consists of two strong $\pi$ bonds + one strong $\sigma$ bond + one weaker $\sigma$-type bond; 3 : the dative bonding model suggested by Hermann and Frenking ${ }^{[22]}$ that consists of two m-type bonds + two weak donor-acceptor bonds; 4: the simplified topological model proposed by the present author and used throughout this article. In this depiction of $\mathrm{C}_{2}$, the dashed lines represent two weak, highly reactive bonds, and the solid lines represent two strong bonds.

conclude that the description of the bonding according to the MO model was inadequate. They instead described $\mathrm{C}_{2}$ as a quadruply-bonded species having three internal bonds consisting of one $\sigma$ bond, two $\pi$ bonds and one weak outer $\sigma$ bond. ${ }^{[21]}$ This is depicted as structure $\mathbf{2}$ in Figure 1. They named this last weak $\sigma$ bond an "inverted" $\mathrm{C}-\mathrm{C}$ bond and labeled it $\sigma_{\text {out }}$ " In one article, Shaik et al. ${ }^{[21 b]}$ suggested that the very high reactivity of $\mathrm{C}_{2}$ is rooted in its fourth, weak bond. Hermann and Frenking ${ }^{[2]}$ challenged the Shaik team's description and, as depicted as structure $\mathbf{3}$ in Figure 1, suggested that the bonding component in $\mathrm{C}_{2}$ consists of two weak donoracceptor $\sigma$ bonds and two strong electron-sharing $\pi$ bonds. Let us point out that according to Frenking and Hermann ${ }^{[23]}$ "there is no single Lewis structure that adequately depicts the bonding situation in $\mathrm{C}_{2}$."

So, the question arises, what is a good way for organic chemists to represent the $\mathrm{C}_{2}$ dimer when visualizing reaction pathways that involve processes such as cycloadditions? As will be substantiated throughout this article, in our view the very high reactivity of $\mathrm{C}_{2}$ is rooted in the presence of two weak bonds. For this reason we believe $\mathrm{C}_{2}$ is best represented by the model proposed by Hermann and Frenking ${ }^{[22]}$ in which the bonding in $\mathrm{C}_{2}$ is described as consisting of two $\pi$ bonds and two week $\sigma$ bonds. However, in this article we do not use the Hermann and Frenking depiction shown as structure $\mathbf{3}$ in Figure 1. Instead, for clarity we use the simplified topological depiction shown as structure 4 in Figure 1, where the solid lines represent the two strong bonds and the dashed lines represent the two weak bonds. In the schemes depicted in this article, these two weak bonds are the ones that actively participate in cycloaddition reactions involving the $\mathrm{C}_{2}$ dimer.

\section{Role of $\mathrm{C}_{2}$ Dimers: Insertions vs. Additions}

There is disagreement among authors that have previously suggested "bottom-up" models regarding the role $\mathrm{C}_{2}$ dimers could play in the formation of fullerenes. Some authors argue that $\mathrm{C}_{2}$ dimers are involved 
in insertion-type reactions while others argue that $\mathrm{C}_{2}$ dimers participate in addition-type reactions.

The view that $\mathrm{C}_{2}$ dimers are involved in insertion reactions was first championed by Endo and Kroto. ${ }^{[2]}$ They proposed that insertion of a $\mathrm{C}_{2}$ dimer into a hexagon situated between two pentagons can serve as a basic mechanism that might be responsible for the growth of fullerenes and carbon nanotubes. In their model, a $\mathrm{C}_{2}$ insertion would result in the hexagon being divided into two adjacent pentagons and two hexagons being formed from the two pentagons. Since the article by Endo and Kroto was published, several other authors offered a variety of "bottomup" growth mechanisms of fullerenes in which $\mathrm{C}_{2}$ dimers are believed to be involved in insertion processes ${ }^{[3 \mathrm{dd}-\mathrm{f}, 25-26]}$ According to other authors, $\mathrm{C}_{2}$ dimers are involved in cycloaddition reactions. For example, to explain the formation of $\mathrm{C}_{60}$ and $\mathrm{C}_{70}$, Chang et al. ${ }^{[5 \mathrm{a}]}$ suggested a mechanism during which carbon clusters grow by the sequential addition of $\mathrm{C}_{2}$ units. In their proposed pathway, the authors show how five pentagonal rings are created following the addition of $\mathrm{C}_{2}$ units to the five zig-zag edge regions (3C bays) harbored by the dehydrogenated $\mathrm{C}_{20}$ carbon cluster exhibiting the carbon skeleton of corannulene. This produces a $\mathrm{C}_{30}$ cluster which features five armchair regions at its rim. Then, a [4+2] cycloaddition type reaction involving a $\mathrm{C}_{2}$ unit at each of the five armchair regions creates five new hexagonal rings, thus producing $\mathrm{C}_{40}$ cluster featuring five new armchair regions. Subsequent [4+2] cycloadditions of five $\mathrm{C}_{2}$ units to these armchair regions result in the formation of $\mathrm{a}_{50}$ carbon cluster containing five new hexagonal rings. Dresselhaus et al. ${ }^{[27]}$ also suggested similar growth sequences. Starting from the $\mathrm{C}_{20}$ cluster exhibiting the carbon skeleton of corannulene, they suggested that pentagonal rings are created following additions of $\mathrm{C}_{2}$ dimers to zig-zag regions of carbon cluster intermediates, and hexagonal rings are created following additions of $\mathrm{C}_{2}$ dimers to bay regions of carbon cluster intermediates.

We propose a novel "bottom-up" model in which $\mathrm{C}_{2}$ dimers are involved in addition processes. Similar to what Chang et al. ${ }^{[5 a]}$ and Dresselhaus et al. ${ }^{[27]}$ had suggested, our proposed growth sequences also include the formation of pentagonal rings as the result of addition $\mathrm{C}_{2}$ dimers to zig-zag regions, and the formation of hexagonal rings as the result of additions of $\mathrm{C}_{2}$ dimers to bay regions. However, and most importantly, we further propose that the $\mathrm{C}_{2}$ dimers also participate in a series of $[2+2+2]$ cycloaddition reactions that are responsible for the formation of hexagonal rings containing conjugated $\pi$ systems. In addition, we suggest that in bowl-shaped carbon clusters isolated pentagonal rings form as the result of: 1) closure of "cove" regions that exist between newly-created hexagonal rings, and; 2) [4+1] cycloaddition processes that occur during cage closure events.

\section{Trapping of Intermediates During Arc- Discharge and Laser Ablation Methods}

The proposed growth sequences that could lead to the formation of fullerenes and PAHs involve successive additions of $\mathrm{C}_{2}$ units that in the process create a series of bare carbon clusters as transient intermediates. Several of these intermediates have been indirectly identified in numerous experiments aimed at trapping them either by hydrogenation ${ }^{[5]}$ or chlorination. ${ }^{[6]}$ Relevant trapping experiments involving hydrogen and chlorine donors are reviewed in what follows. a
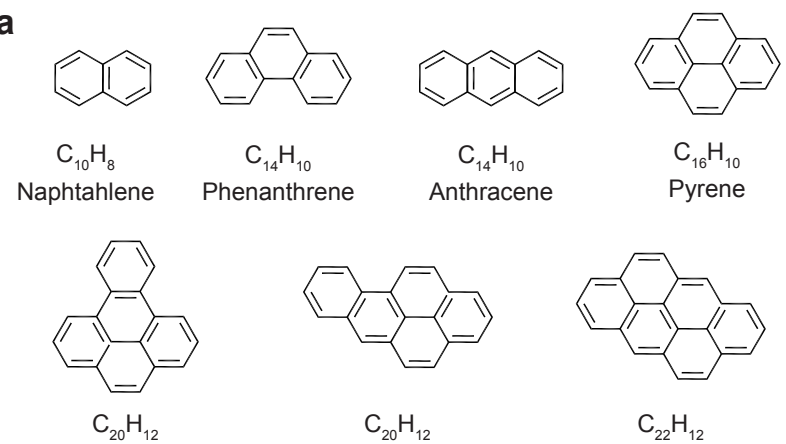

$$
\mathrm{C}_{14} \mathrm{H}_{10}
$$

Phenanthrene

\section{$\mathrm{C}_{14} \mathrm{H}_{10}$} Anthracene
$\mathrm{C}_{16} \mathrm{H}_{10}$

Pyrene
Benzo[e]pyrene

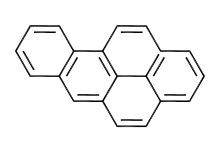

$\mathrm{C}_{20} \mathrm{H}_{12}$

Benzo[a]pyrene

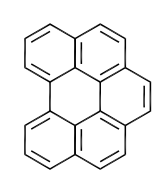

$\mathrm{C}_{10} \mathrm{H}_{8}$

Benzo[ghi]perylene

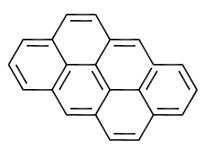

$\mathrm{C}_{22} \mathrm{H}_{12}$

Ananthracene

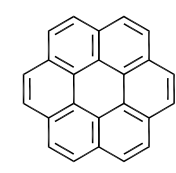

$\mathrm{C}_{24} \mathrm{H}_{12}$

Coronene

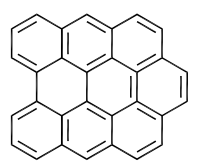

$\mathrm{C}_{30} \mathrm{H}_{14}$

Dibenzo[bc,ef ]coronene

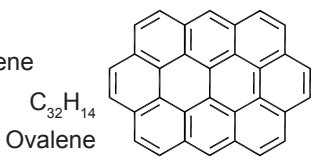

b

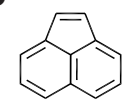

$\mathrm{C}_{12} \mathrm{H}_{8}$ Acenaphtylene

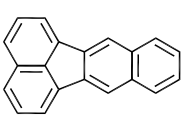

$\mathrm{C}_{20} \mathrm{H}_{12}$

Benzo[k]-

fluoranthene

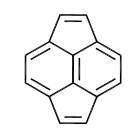

$\mathrm{C}_{14} \mathrm{H}_{8}$ Pyracylene

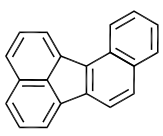

$\mathrm{C}_{20} \mathrm{H}_{12}$ Benzo[j]fluoranthene

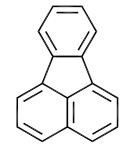

$\mathrm{C}_{16} \mathrm{H}_{10}$ Fluoranthene

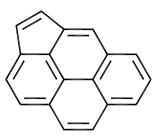

$\mathrm{C}_{18} \mathrm{H}_{10}$

Cyclopenta[c,d]- Indeno[1,

pyrene

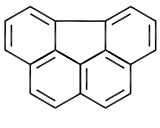

$\mathrm{C}_{18} \mathrm{H}_{10}$ Benzo[ghi]fluoranthene

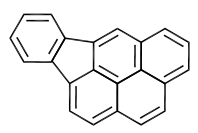

$\mathrm{C}_{24} \mathrm{H}_{12}$ no[1,2,3-cd]pyrene
Figure 2. Structure of PAHs produced as the result of trapping of bare carbon clusters by hydrogenation during processes that involve arc-discharge or laser ablation of graphite. ${ }^{[5]}$ a) PAHs with only hexagonal rings; b) PAHs containing one or two pentagonal rings.

\subsection{Trapping by Hydrogenation}

Chang et al. ${ }^{[5]}$ reported that addition of hydrogen donors, such as propene or methanol, to systems in which $\mathrm{C}_{60}$ and $\mathrm{C}_{70}$ were generated resulted in the formation of PAHs such as $\mathrm{C}_{12} \mathrm{H}_{8}$ (acenaphtylene), $\mathrm{C}_{14} \mathrm{H}_{12}$ (phenanthrene), $\mathrm{C}_{16} \mathrm{H}_{10}$ (fluoranthene), $\mathrm{C}_{16} \mathrm{H}_{10}$ (pyrene), and $\mathrm{C}_{18} \mathrm{H}_{10}$ (benzo[ghi]fluoranthene). These compounds presumably resulted from hydrogenation of bare carbon clusters such as, $\mathrm{C}_{12}, \mathrm{C}_{14}, \mathrm{C}_{16}$ and $\mathrm{C}_{18}$, which could be considered subunits of the $\mathrm{C}_{60}$ fullerene or large PAHs. The Chang team observed an increase in trapping products with a corresponding decrease in $\mathrm{C}_{60}$ as the concentration of hydrogen donors was increased. According to these authors, these observations are consistent with the 
hypothesis that the dehydrogenated clusters form as intermediates during growth routes to fullerenes and PAHs.

The trapping of intermediates via hydrogenation was also performed by Zumwalt. ${ }^{[5 b]}$ This author studied the effect of introducing hydrogen into the carbon-arc process of fullerene formation with the goal of "freezing out" molecules that lie along the pathway to fullerene formation. Analytical results of this study showed that the fullerene yield decreased with increasing hydrogen presence. In addition, analysis showed that numerous PAHs were also produced in larger quantities and larger molecular sizes as the amount of hydrogen poisoning increased. The PAHs that were identified included compact, hexagon-only PAHs such as pyrene, perylene, benzo[ghi]perylene, coronene and ovalene. It also included a class of cyclopenta-fused PAHs such as fluoranthene, aceanthrylene, benzo[ghi]fluoranthene, benzo[j]fluoranthene, benzo[k]fluoranthene, indeno[1,2,3-cd]fluoranthene and indeno[1,2,3-cd]pyrene. Let us point out that Zumwalt ${ }^{[5 b]}$ also reported that acetylene was the major component of the gas that was produced during his carbon-arc experiment that was performed in an atmosphere containing $\mathrm{H}_{2}$ molecules. While acetylene was not detectable at $0 \% \mathrm{H}_{2}$, its presence rose from 6,000 to $110,000 \mathrm{ppm}$ in $\mathrm{H}_{2}$ levels of $15 \%$ and $80 \%$, respectively. In our view, the formation of acetylene resulted from the hydrogenation of $\mathrm{C}_{2}$ dimers that were produced during this carbon-arc process.

In a study similar to Zumwalt's, De Vries et al. ${ }^{[5 c]}$ also showed that PAHs replaced fullerenes as stable end products when hydrogen was present during a process where graphite was ablated with a laser in an atmosphere of $\mathrm{Ar}$ and $\mathrm{H}_{2}$. Results from De Vries' team showed that: 1) with no $\mathrm{H}_{2}$ present, even-numbered carbon clusters up to at least $\mathrm{C}_{220}$ were produced and among these clusters the $\mathrm{C}_{60}$ and $\mathrm{C}_{70}$ signals were predominant; 2) with $0.4 \% \mathrm{H}_{2}$, fullerene formation was reduced at the same time prominent PAHs in the 100 to 400 amu mass range appeared, and; 3) with $10 \% \mathrm{H}_{2}$ present, PAHs were the only products collected; no more fullerenes were observed. In regards to PAHs in the ISM, De Vries' team pointed out that the distribution of the PAHs generated in their experiments shares similarity with the distribution of PAHs that they identified in the Murchison and Allende meteorites.

Wilson et al. ${ }^{[5 \mathrm{~d}]}$ reported similar formations of numerous PAHs as the result of electrical arcing of graphite in the presence of methane acting as a hydrogen donor. Included among the PAHs that were produced during these processes were odd-PAHs such as fluorene, cyclopenta[def] phenanthrene, and benzo[a]fluorene.

An important number of PAHs were also produced along with the $\mathrm{C}_{60}$ fullerene by Beck et al. ${ }^{[5 \mathrm{e}]}$ following electric discharges between graphite electrodes in liquid toluene. Included among the PAHs identified in this study were naphthalene, acenaphthylene, pyracylene, anthracene, phenanthrene, pyrene, chrysene, benzo[g,h,i]fluoranthene, benzo[k]fluoranthene, perylene, and benzo[ghi]perylene. Shown in Figure 2 are the structures of relevant PAHs that were identified in the aforementioned experiments aimed to trap carbon clusters by hydrogenation.

\subsection{Trapping by Chlorination}

Chlorination of peripheral atoms of carbon clusters was also used in several experiments to trap intermediates. Grösser and Hirsch ${ }^{[6 a]}$ carried out graphite arc-discharge experiments in presence of dichlorine $\left(\mathrm{Cl}_{2}\right)$ and identified numerous chlorinated carbon clusters (CCCs) such as hexachlorobenzene $\left(\mathrm{C}_{6} \mathrm{Cl}_{6}, 60 \%\right)$, octachloroacenaphthylene $\left(\mathrm{C}_{12} \mathrm{Cl}_{8}\right.$, $9 \%$ ), and other $\mathrm{CCCs}$ (in total 17\%) that included decachlorocorannulene $\left(\mathrm{C}_{20} \mathrm{Cl}_{10}\right)$.

Similar CCCs were produced by Zheng et al. ${ }^{[6 b]}$ during experiments
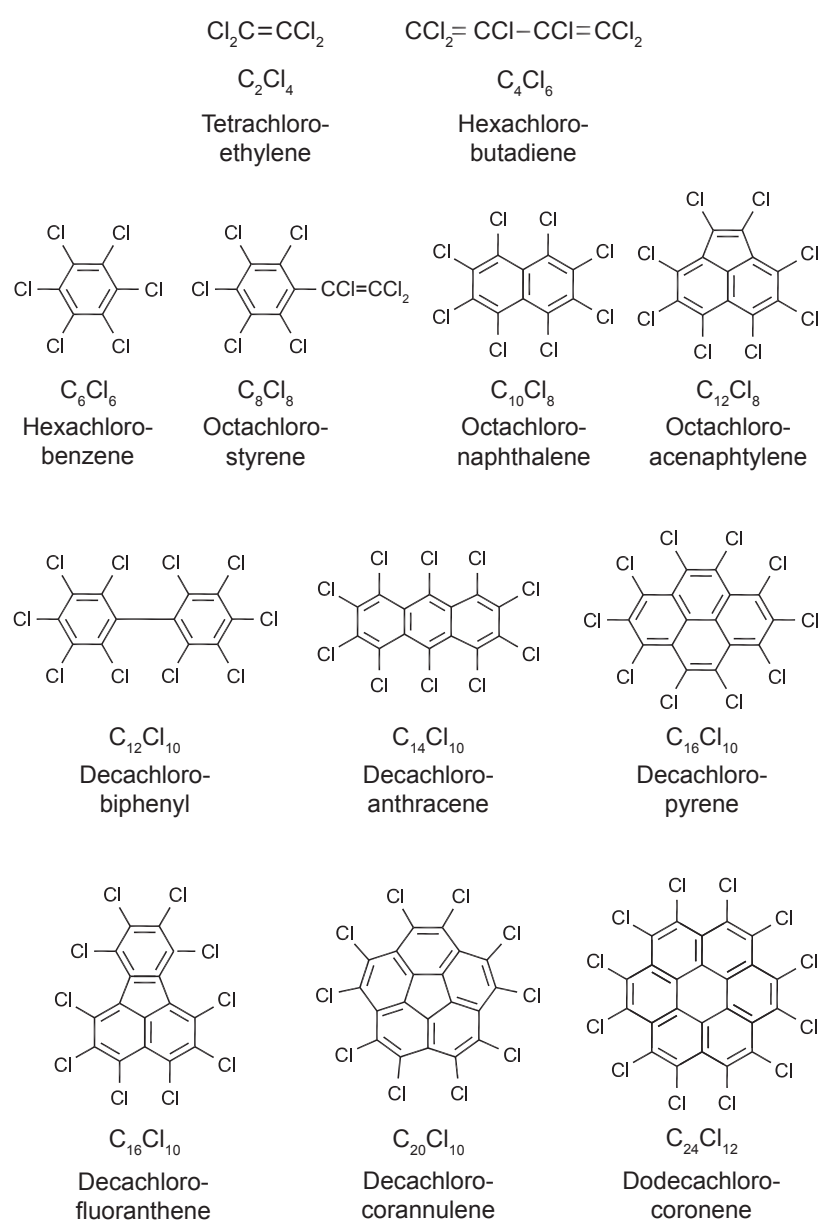

Figure 3. Structure of chlorinated compounds produced as the result of trapping of bare carbon clusters by chlorination during processes that involve graphite arc-discharge experiments. ${ }^{[6]}$

involving discharge in liquid chloroform. They showed that among the products, tetrachloroethylene $\left(\mathrm{C}_{2} \mathrm{Cl}_{4}\right)$, hexachlorobutadiene $\left(\mathrm{C}_{4} \mathrm{Cl}_{6}\right)$, and hexachlorobenzene $\left(\mathrm{C}_{6} \mathrm{Cl}_{6}\right)$ were the most abundant. During this process octachlorostyrene $\left(\mathrm{C}_{8} \mathrm{Cl}_{8}\right)$ and octachloronaphthalene $\left(\mathrm{C}_{10} \mathrm{Cl}_{8}\right)$ were produced in relatively good yield. Let us point out that, during those trapping experiments, the formation of $\mathrm{C}_{2} \mathrm{Cl}_{4}$ provides direct evidence of the presence of $\mathrm{C}_{2}$ dimers participating in the growth processes. In this regard it is worth mentioning that $\mathrm{C}_{2} \mathrm{Cl}_{4}$ was produced by Skell et al. ${ }^{[28]}$ in an experimental process during which $\mathrm{C}_{2}$ was allowed to react with chlorine. To explain the results of the trapping experiment performed by Zheng et al., ${ }^{[6 b]}$ we can reasonably assume that the following processes took place: 1) the $\mathrm{C}_{4} \mathrm{Cl}_{6}$ compound resulted from the chlorination of a linear- $\mathrm{C}_{4}$ cluster; 2) the $\mathrm{C}_{6} \mathrm{Cl}_{6}$ compound resulted from chlorination of the cyclic- $\mathrm{C}_{6}$ cluster that exhibits the carbon skeleton of benzene; 3 ) the $\mathrm{C}_{8} \mathrm{Cl}_{8}$ compound resulted from chlorination of the $\mathrm{C}_{8}$ cluster that has the carbon skeleton of phenyl acetylene, and; 4) the $\mathrm{C}_{10} \mathrm{Cl}_{8}$ compound resulted from the chlorination of the $\mathrm{C}_{10}$ cluster that has the carbon skeleton of naphthalene. Zheng et al. ${ }^{[6 c]}$ also performed graphite arc-discharge experiments in an atmosphere consisting of $\mathrm{CCl}_{4}$ and $\mathrm{He}$. In addition to yielding graphite, as well as $\mathrm{C}_{60}$ and $\mathrm{C}_{70}$ fullerenes, these experiments yielded a variety of CCCs including hexachlorobenzene $\left(\mathrm{C}_{6} \mathrm{Cl}_{6}\right)$, octachlronaphthalene $\left(\mathrm{C}_{10} \mathrm{Cl}_{8}\right)$, octachloroacenaphthylene $\left(\mathrm{C}_{12} \mathrm{Cl}_{8}\right)$, decachlorofluoranthene 
$\left(\mathrm{C}_{16} \mathrm{Cl}_{10}\right)$, decachloropyrene $\left(\mathrm{C}_{16} \mathrm{Cl}_{10}\right)$, and two isomers of $\mathrm{C}_{18} \mathrm{Cl}_{10}$. Also detected in these experiments were larger decachlorinated carbon clusters such as $\mathrm{C}_{22} \mathrm{Cl}_{10}, \mathrm{C}_{28} \mathrm{Cl}_{10}$ and $\mathrm{C}_{50} \mathrm{Cl}_{10}$. This Zheng team showed evidence that the yields of some CCCs corresponded well with the yield of $\mathrm{C}_{60}$, thus implying that these CCCs share the same growth mechanism with fullerenes. In another experimental study, Zheng et al. ${ }^{[6 \mathrm{dd}]}$ separated and identified over 100 perchlorinated polycyclic aromatic hydrocarbon (PCPAHs). These compounds included decachlrobiphenyl $\left(\mathrm{C}_{12} \mathrm{Cl}_{10}\right)$, decachlrophenanthrene $\left(\mathrm{C}_{14} \mathrm{Cl}_{10}\right)$, decachlroanthracene $\left(\mathrm{C}_{14} \mathrm{Cl}_{10}\right)$, and dodecachloroconene $\left(\mathrm{C}_{24} \mathrm{Cl}_{12}\right)$.

Recently Fazekas et al. ${ }^{[6 \mathrm{e}]}$ reported that similar CCCs were produced together with the $\mathrm{C}_{60}$ and $\mathrm{C}_{70}$ fullerenes as the result of the thermal plasma decomposition of tetrachoroethylene $\left(\mathrm{C}_{2} \mathrm{Cl}_{4}\right)$. Let us note that during these thermal plasma experiments, carbon dimers were detected with the help of optical emission spectra that showed the presence of intensive $\mathrm{C}_{2}$ Swan bands. Most likely in this study, the $\mathrm{C}_{2}$ dimers were produced as the result of dechlorination of $\mathrm{C}_{2} \mathrm{Cl}_{4}$. Shown in Figure 3 are the structures of relevant chlorinated PAHs that were identified in the aforementioned experiments aimed to trap bare carbon clusters by chlorination processes.

From the variety of trapping experiments that were reviewed in Section 4 we can imply that bare carbon clusters, which when hydrogenated give rise to a large variety of PAHs and when chlorinated yield various chloroPAHs, share the same growth mechanisms with cluster intermediates that could be identified as fullerene fragments.

\section{Proposed Routes to $I_{\mathrm{h}}-\mathrm{C}_{60}$}

\subsection{Routes to Cyclic $\mathrm{C}_{6}$ and Bicyclic $\mathrm{C}_{10}$}

In this section we propose a series of growth sequences that could be responsible for the formation, via additions of $\mathrm{C}_{2}$ dimers acting as growth species, of: 1) linear $\mathrm{C}_{2 \mathrm{n}}$ clusters; 2) the cyclic $\mathrm{C}_{6}$ cluster that exhibits

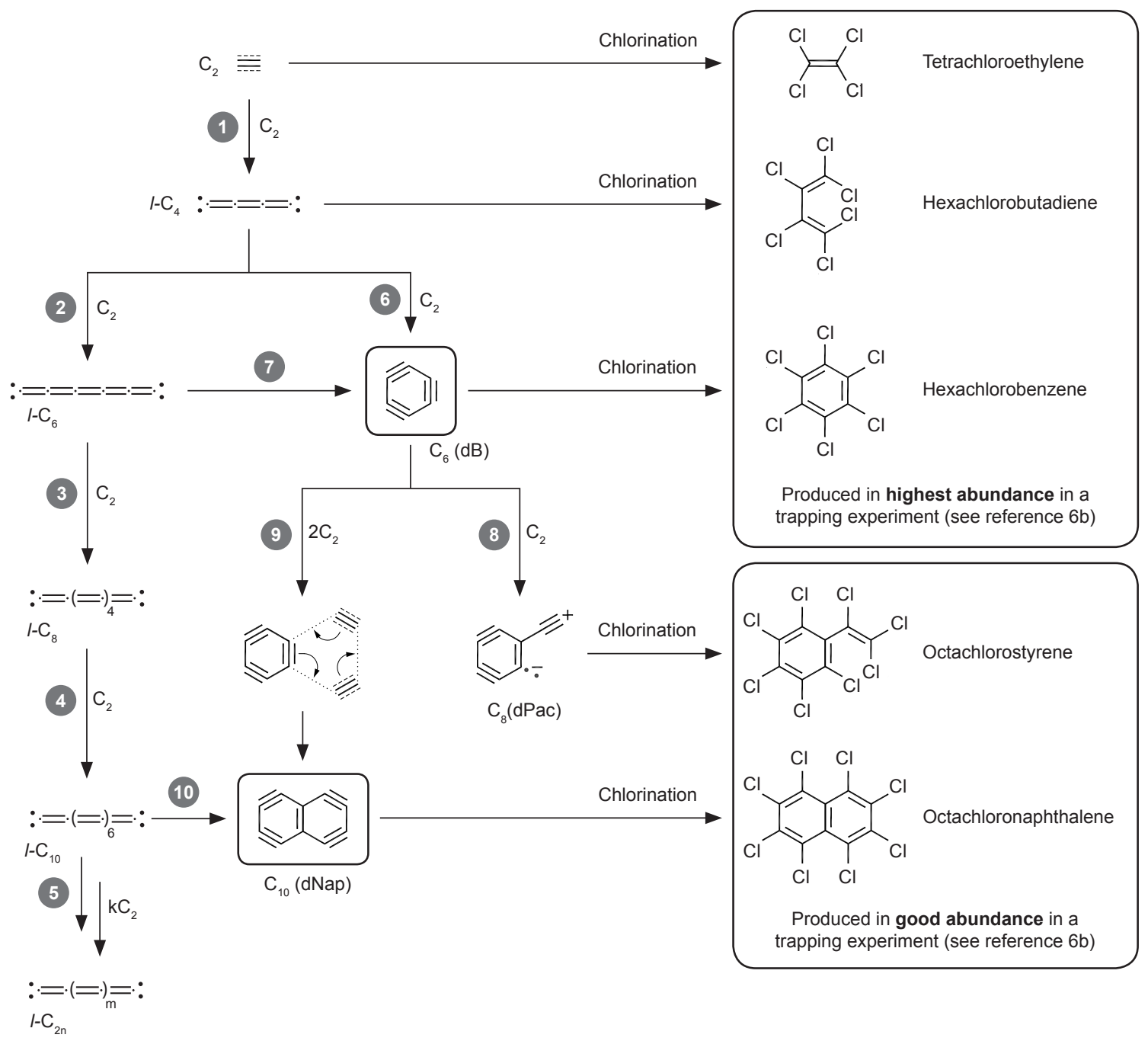

Scheme 1. Proposed growth mechanism for the formation, via sequential addition of $C_{2}$ dimers, of: 1) linear carbon chains; 2 ) the cyclic $C_{6}$ cluster that exhibits the carbon skeleton of benzene; 3 ) the $C_{8}$ cluster that exhibits the carbon skeleton of phenylacetylene, and; 4 ) the bicyclic $C_{10}$ cluster that exhibits the carbon skeleton of naphthalene. Shown in the boxes on the right are the structures of chlorinated compounds that would be produced as the result of trapping by chlorination of the $\mathrm{C}_{2}$ dimer, the linear $\mathrm{C}_{4}$ cluster, the cyclic $\mathrm{C}_{6}$ cluster the $\mathrm{C}_{8}$ cluster and the bicyclic $\mathrm{C}_{10}$ cluster. 
the carbon skeleton of benzene; 3 ) the $\mathrm{C}_{8}$ cluster that exhibits the carbon skeleton of phenylacetyylene, and; 4) the bicyclic $\mathrm{C}_{10}$ cluster that exhibits the carbon skeleton of naphthalene. As mentioned in Section 4.2, we suggested that these clusters were trapped by chlorination resulting in the $\mathrm{C}_{2}$ dimer being trapped as $\mathrm{C}_{2} \mathrm{Cl}_{4}$ (terachloroethylene); the linear $\mathrm{C}_{4}$ cluster being trapped as $\mathrm{C}_{4} \mathrm{Cl}_{6}$ (hexachlorobutadiene); the cyclic- $\mathrm{C}_{6}$ cluster being trapped as $\mathrm{C}_{6} \mathrm{Cl}_{6}$ (hexachlorobenzene), the $\mathrm{C}_{8}$ clusterbeing trapped as $\mathrm{C}_{8} \mathrm{Cl}_{8}$ (octachlorostyene), and; the bicyclic- $\mathrm{C}_{10}$ cluster being trapped as $\mathrm{C}_{10} \mathrm{Cl}_{8}$ (octachloronaphthalene).

In the present article, to label dehydrogenated cyclic clusters, we use a convention where "d" stands for "dehydrogenated," which is followed by a capitalized abbreviation of the cyclic cluster. For example, $\mathrm{C}_{6}(\mathrm{~dB})$ stands for "dehydrogenetad benzene," and $\mathrm{C}_{10}(\mathrm{dNap})$ stands for "dehydrogenated naphthalene."

Illustrated in Scheme 1 are the steps of the proposed routes to the linear- $\mathrm{C}_{2 \mathrm{n}}$ clusters, the cyclic- $\mathrm{C}_{6}(\mathrm{~dB})$ cluster that exhibits the carbon skeleton of benzene, the $\mathrm{C}_{8}(\mathrm{dPac})$ cluster that exhibits the carbon skeleton of phenylacetylene, and the bicyclic- $\mathrm{C}_{10}(\mathrm{dNap})$ cluster that exhibits the carbon skeleton of naphthalene:

Step 1: Interaction between two $\mathrm{C}_{2}$ dimers produces the linear- $\mathrm{C}_{4}$ cluster $\left(l-\mathrm{C}_{4}\right)$. As indicated in the review by Van Order and Saykally, ${ }^{[29]}$ the bonding of the linear- $\mathrm{C}_{4}$ in the ground state exhibits a cumulene type character.

Step 2: Addition of one $\mathrm{C}_{2}$ dimer at the end of the $l-\mathrm{C}_{4}$ cluster yields the linear- $\mathrm{C}_{6}$ cluster $\left(l-\mathrm{C}_{6}\right)$. The cumulene character of the ground electronic state of the $l-\mathrm{C}_{6}$ cluster was confirmed in a study by Masso and Sentent ${ }^{[30]}$ although, as indicated by these authors, no barriers of energy prevent the interconversion from the cumulene to the acetylene form.

Steps 3 and 4: Starting from the $l-\mathrm{C}_{6}$ cluster, further $\mathrm{C}_{2}$ additions produce linear- $\mathrm{C}_{8}\left(l-\mathrm{C}_{8}\right)$ and then linear- $\mathrm{C}_{10}\left(l-\mathrm{C}_{10}\right)$.

Step 5: Starting from linear- $\mathrm{C}_{10}$, further additions of $\mathrm{C}_{2}$ dimers produce linear- $\mathrm{C}_{2 \mathrm{n}}$ clusters, shown here in their cumulenic form.

Step 6: $\mathrm{A}[4+2]$ cycloaddition reaction between one $\mathrm{C}_{2}$ dimer and the $l-\mathrm{C}_{4}$ cluster leads to the formation of the cyclic $\mathrm{C}_{6}(\mathrm{~dB})$ cluster that features three "triple bonds" each of which is similar to the "triple bond" shown in ortho-arynes. In this article, this bonding type is referred to as a "triple bond." The cyclic- $\mathrm{C}_{6}$ cluster has been given various names including hexadehydrobenzene, benzotriyne, cyclo-1,3,5-triyne, and cyclo[6]carbon.

Step 7: In this step another route to the $\mathrm{C}_{6}(\mathrm{~dB})$ cluster is suggested. This route involves the cyclization of the linear- $\mathrm{C}_{6}$ cluster. Let us note that such a route was envisioned by Pascoli and Polleux ${ }^{[31]}$ who reported that density functional theory (DFT) calculations gave a small value of 1.11 $\mathrm{eV}$ for the activation barrier for conversion of linear- $\mathrm{C}_{6}$ into the cyclic form. Regarding cyclic- $\mathrm{C}_{6}$, it is worth mentioning an experimental study by Adamson and Rees ${ }^{[32]}$ in which they attempted to create cyclic- $\mathrm{C}_{6}$ in a process used to create ortho-arynes. They reported the formation of cyclic- $\mathrm{C}_{6}$ and other products, one of which showed the mass spectral evidence of trace quantities of a species with the same $\mathrm{M}^{+}$as $\mathrm{C}_{60}$. It can be interpreted, that in this experiment, cyclic- $\mathrm{C}_{6}$ most likely participates in the route to $\mathrm{C}_{60}$.

Step 8: Addition reaction involving of one $\mathrm{C}_{2}$ dimer and the $\mathrm{C}_{6}(\mathrm{~dB})$ cluster results in the formation of the $\mathrm{C}_{8}(\mathrm{dPac})$ cluster.

Step 9: $\mathrm{A}[2+2+2]$ cycloaddition reaction involving one "triple bond" of $\mathrm{C}_{6}(\mathrm{~dB})$ and two $\mathrm{C}_{2}$ dimers results in the formation of $\mathrm{C}_{10}(\mathrm{dNap})$. This proposed route to the $\mathrm{C}_{10}(\mathrm{dNap})$ cluster shares similarities with the catalyzed $[2+2+2]$ cycloaddition processes that produces compounds having the carbon skeleton of naphthalene as the result of benzynes reacting with electron-deficient alkynes ${ }^{[33]}$ The formation of the $\mathrm{C}_{10}(\mathrm{dNap})$ cluster could also result from a [4+2] cycloaddition reaction between the $l$ - $\mathrm{C}_{4}$ cluster and the $\mathrm{C}_{6}(\mathrm{~dB})$ cluster.
Step 10: This depicts another possible route to the $\mathrm{C}_{10}(\mathrm{dNap})$ cluster that involves the isomerization of the linear- $\mathrm{C}_{10}$ cluster. Let us mention that such a route was suggested by Pascoli and Polleux. ${ }^{[31]}$

In the boxes drawn in Scheme 1 are structures of chlorinated carbon clusters that would have been produced as the result of trapping by chlorination during experiments performed by Zheng et al. ${ }^{[6 b]}$ Chlorination of the: 1) $\mathrm{C}_{2}$ dimer would yield tetrachloroethylene; 2) linear $\mathrm{C}_{4}$ would yield hexachlorobutadiene; 3 ) cyclic $\mathrm{C}_{6}$ would yield hexachlorobenzene; 4) $\mathrm{C}_{8}$ cluster (having the carbon skeleton of phenylacetylene) would yield octachlorostyrene, and; 5) bicyclic $\mathrm{C}_{10}$ would yield octachloronaphthalene.

Note that in Scheme 1, as well as the other schemes of the present article, the proposed cycloaddition processes are depicted as taking place in concerted manners. These suggested depictions are based on numerous studies ${ }^{[34]}$ showing that reactions that involve the "triple bond" of arynes such as $[2+2]$ cycloadditions, ${ }^{[34 a-b]}$ [4+2] Diels-Alder reactions, ${ }^{[34 c-d]}$ ene-reactions, ${ }^{[34 \mathrm{e}]}$ and $\mathrm{H} 2$-transfers, ${ }^{[34-\mathrm{g}]}$ occur via one-step concerted mechanisms. Let us point out that during these processes, the "triple bond" behaves as a strained alkyne rather than a biradical. Regarding the $\mathrm{H}_{2}$-transfer reaction, it is important to note that authors reported that these processes leading to aryne hydrogenation do not involve addition of $\mathrm{H}$ atoms to radical species. Instead, it was shown that these processes could occur as the result of the simultaneous (i.e. concerted) removal of two adjacent (vicinal) hydrogen atoms from a hydrocarbon, ${ }^{[34 f]}$ or as the result of the simultaneous (i.e. concerted) removal of the carbinol C-H and adjacent $\mathrm{O}-\mathrm{H}$ hydrogen atom from an alcohol. ${ }^{[34 \mathrm{~g}]}$

\subsection{Routes to $C_{20}$ Bowl from $C_{6}$ and $C_{10}$}

In this section we propose two growth sequences that could be responsible for the formation of the $\mathrm{C}_{20}$ bowl intermediate. These growth sequences involve the creation of $\mathrm{C}_{12}, \mathrm{C}_{14}, \mathrm{C}_{16}, \mathrm{C}_{18}$ and $\mathrm{C}_{20}$ bare carbon clusters that exhibit the carbon skeleton of acenaphtylene, phenanthrene, fluoranthene, benzo[ghi]fluoranthene, and corannulene, respectively. As mentioned in section 4, these last bare carbon clusters have been trapped by hydrogenation or chlorination (see Figures 2 and 3). The two proposed growth routes to $\mathrm{C}_{20}$ bowl are depicted in Scheme 2:

Growth sequence A:

Step A1: The $\mathrm{C}_{10}(\mathrm{dNap})$ cluster exhibits four "triple bonds" at its periphery. $\mathrm{A}[2+2+2]$ cycloaddition process that involves the $\mathrm{C} 5-\mathrm{C} 6$ "triple bond" and two $\mathrm{C}_{2}$ dimers produces the $\mathrm{C}_{14}(\mathrm{dPh})$ cluster that has the carbon skeleton of Phenanthrene. This $\mathrm{C}_{14}(\mathrm{dPhe})$ cluster could also form as the result a $[2+2+2]$ cycloaddition reaction between two $\mathrm{C}_{6}(\mathrm{~dB})$ clusters and one $\mathrm{C}_{2}$ dimer (not depicted in Scheme 2).

Step A2: The $\mathrm{C}_{14}$ (dPhe) cluster features five "triple bonds" at its rim. $\mathrm{A}[2+2+2]$ cycloaddition process involving the $\mathrm{C} 3-\mathrm{C} 4$ "triple bond" and two $\mathrm{C}_{2}$ units produces the $\mathrm{C}_{18}(\mathrm{dBcPhe})$ cluster that has the carbon skeleton of benzo[c]phenanthrene.

Step A3: The $\mathrm{C}_{18}(\mathrm{dBcPhe})$ cluster, that exhibits six "triple bonds" at its rim, contains a "cove" region located between the $\mathrm{C} 1-\mathrm{C} 2$ and $\mathrm{C} 11-\mathrm{C} 12$ "triple bonds." As depicted in Scheme 2, this "cove" region closes up to a pentagonal ring as the result of interactions between these two adjacent "triple bonds" that are in close proximity to each other. This leads to the formation of the $\mathrm{C}_{18}(\mathrm{dBghiFlu})$ cluster that exhibits the carbon skeleton of benzo[ghi]fluoranthene. This cluster harbors a bay region that displays a 1,4 zwitterionic character.

Step A4: Addition of one $\mathrm{C}_{2}$ to the bay region of the $\mathrm{C}_{18}$ (dBghiFlu) cluster gives rise to the $\mathrm{C}_{20}$ bowl cluster. Shown in Scheme 2 is a 3D depiction of the $\mathrm{C}_{20}$ bowl, its curvature being caused by the pentagon at its center. Note, this step is identical to Step B3, which is discussed in 


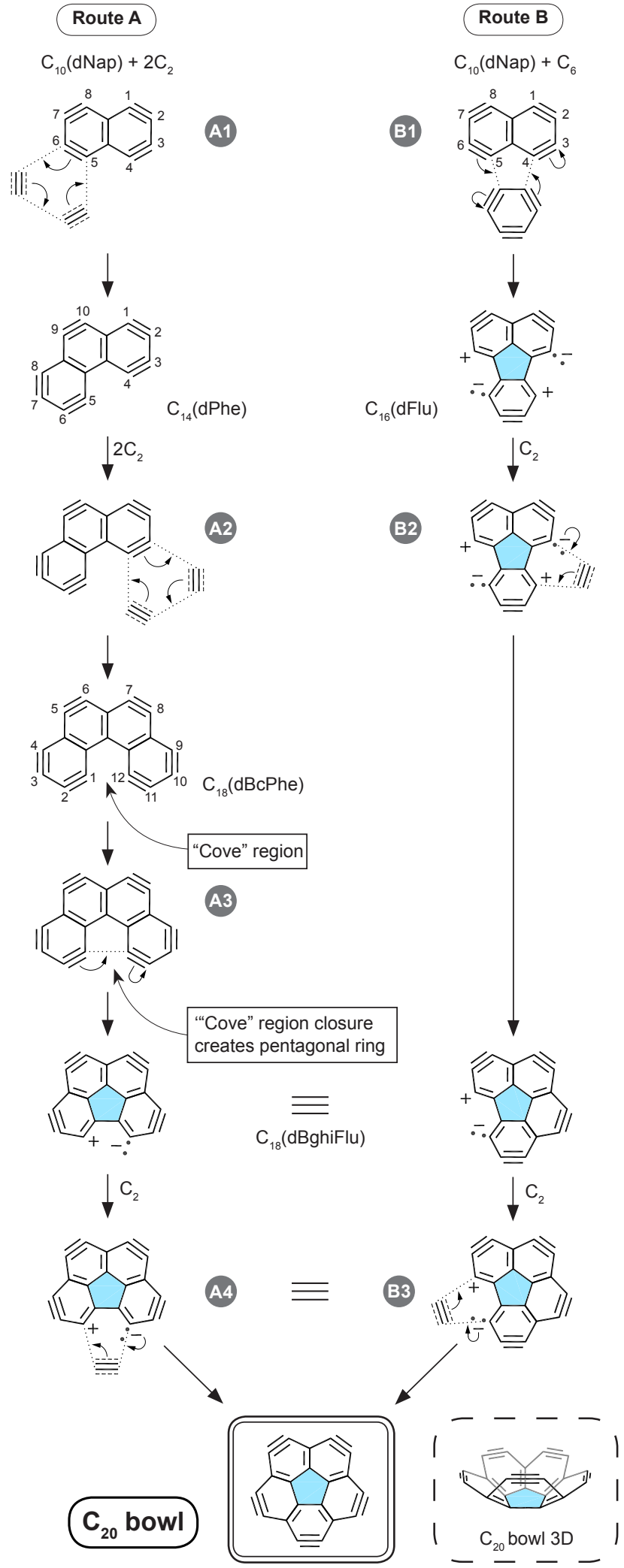

Scheme 2. Two proposed growth mechanisms for the formation, via sequential addition of $\mathrm{C}_{2}$ dimers, of the $\mathrm{C}_{20}$ bowl cluster that possesses the carbon skeleton of corannulene. what follows.

Growth sequence B:

Step B1: The $\mathrm{C}_{10}(\mathrm{dNap})$ cluster harbors two zig-zag edge regions (3C bays). Addition of the $\mathrm{C}_{6}(\mathrm{~dB})$ cluster to one of those zig-zag edges leads to the formation of the $\mathrm{C}_{16}(\mathrm{dFlu})$ cluster that has the carbon skeleton of fluoranthene. This proposed route to $\mathrm{C}_{16}(\mathrm{dFlu})$ shares some similarities with a reaction performed in 1965 by Reese and Storr ${ }^{[35]}$ who showed that 9,14-dihydrofluoranthene formed as the result of the addition of benzene to the zig-zag region of peri-naphthalyne (1,8-dehydronaphthalene). Another possible route (not depicted) to the $\mathrm{C}_{16}(\mathrm{dFlu})$ cluster could also take place in the following manner: First, addition of one $\mathrm{C}_{2}$ dimer to one zig-zag edge of the $\mathrm{C}_{10}(\mathrm{dNap})$ cluster gives rise to the $\mathrm{C}_{12}(\mathrm{dAcPh})$ cluster that has the carbon skeleton of acenaphthylene. This $\mathrm{C}_{12}$ cluster features a pentagonal ring containing a "triple bond." Secondly, a $[2+2+2]$ cycloaddition involving this newly-formed "triple bond" and two $\mathrm{C}_{2}$ dimers produces the $\mathrm{C}_{16}(\mathrm{dFlu})$. As shown in Scheme 2, the $\mathrm{C}_{16}(\mathrm{dFlu})$ cluster harbors two bay regions that exhibit a 1,4 zwitterionic character.

Step B2: Addition of one $\mathrm{C}_{2}$ dimer to one of the two bay regions of the $\mathrm{C}_{16}(\mathrm{dFlu})$ cluster produces the $\mathrm{C}_{18}(\mathrm{dBghiFlu})$ that has the carbon skeleton of benzo[ghi]fluoranthene. This newly-formed $\mathrm{C}_{18}$ cluster harbors one bay region.

Step B3: Addition of one $\mathrm{C}_{2}$ unit to the bay region of $\mathrm{C}_{18}$ (dBghiFlu) results in the formation of the $\mathrm{C}_{20}$ bowl cluster. Note, this step is identical to Step A4.

\subsection{Routes to $I_{h}-C_{60}$ from $C_{20}$ Bowl}

The following proposed growth sequence starting from the $\mathrm{C}_{20}$ bowl cluster and leading to $I_{\mathrm{h}}-\mathrm{C}_{60}$ fullerene is depicted in Scheme 3, which includes Schlegel projections a well as simplified 3D representations.

Step 1: The $\mathrm{C}_{20}$ bowl features five "triple bonds" at its periphery. $\mathrm{A}[2+2+2]$ cycloaddition process, involving each "triple bond" reacting with two $\mathrm{C}_{2}$ dimers, leads to the formation of the $\mathrm{C}_{40}$ (dpBCor) cluster that contains five new six-membered rings with each ring exhibiting the structure of a 1,3-bis-aryne. The $\mathrm{C}_{40}(\mathrm{dpBC}$ or) cluster that exhibits the carbon skeleton of pentabenzo-corannulene has a bowl-shaped geometry caused by the pentagonal ring at its center.

Step 2: The $\mathrm{C}_{40}(\mathrm{dpBCor})$ intermediate harbors five "cove" regions located between pairs of adjacent "triple bonds." Each "cove" region closes up to a pentagonal ring as the result of interactions between pairs of adjacent "triple bonds" that, due to the bowl-shaped geometry of the $\mathrm{C}_{40}(\mathrm{dpBCor})$ intermediate, are located in very close proximity to each other. The "cove" closure event creates five new pentagonal rings and leads to the formation of a bowl-shaped intermediate labeled $\mathrm{C}_{40}(\mathrm{a})$. It is important to note that the five newly-created pentagonal rings end up being non-adjacent because they form as the result of transannular bridging between hexagonal rings.

Step 3: The $\mathrm{C}_{40}(\mathrm{a})$ intermediate harbors five bay regions with each exhibiting a zwitterionic character. Each one of these bay regions is involved in a [4+2] cycloaddition with a $\mathrm{C}_{2}$ dimer. This produces a bowlshaped intermediate labeled $\mathrm{C}_{50}$ (a) that contains five new six-membered rings each of which exhibits the structure of a benzyne ring.

Step 4: The $\mathrm{C}_{50}$ (a) cluster features at its periphery five bay regions that are separated by five "triple bonds." The Schlegel as well as the schematic 3D depictions illustrate how interactions between five $\mathrm{C}_{2}$ dimers and the $\mathrm{C}_{50}$ a) cluster result in a cage closure event. During these interactions the direction of each $\mathrm{C}_{2}$ dimer is perpendicular to middle bond the bay region it is facing. This orientation enables each $\mathrm{C}_{2}$ dimer to interact with two "triple bonds" leading to the formation of five new 


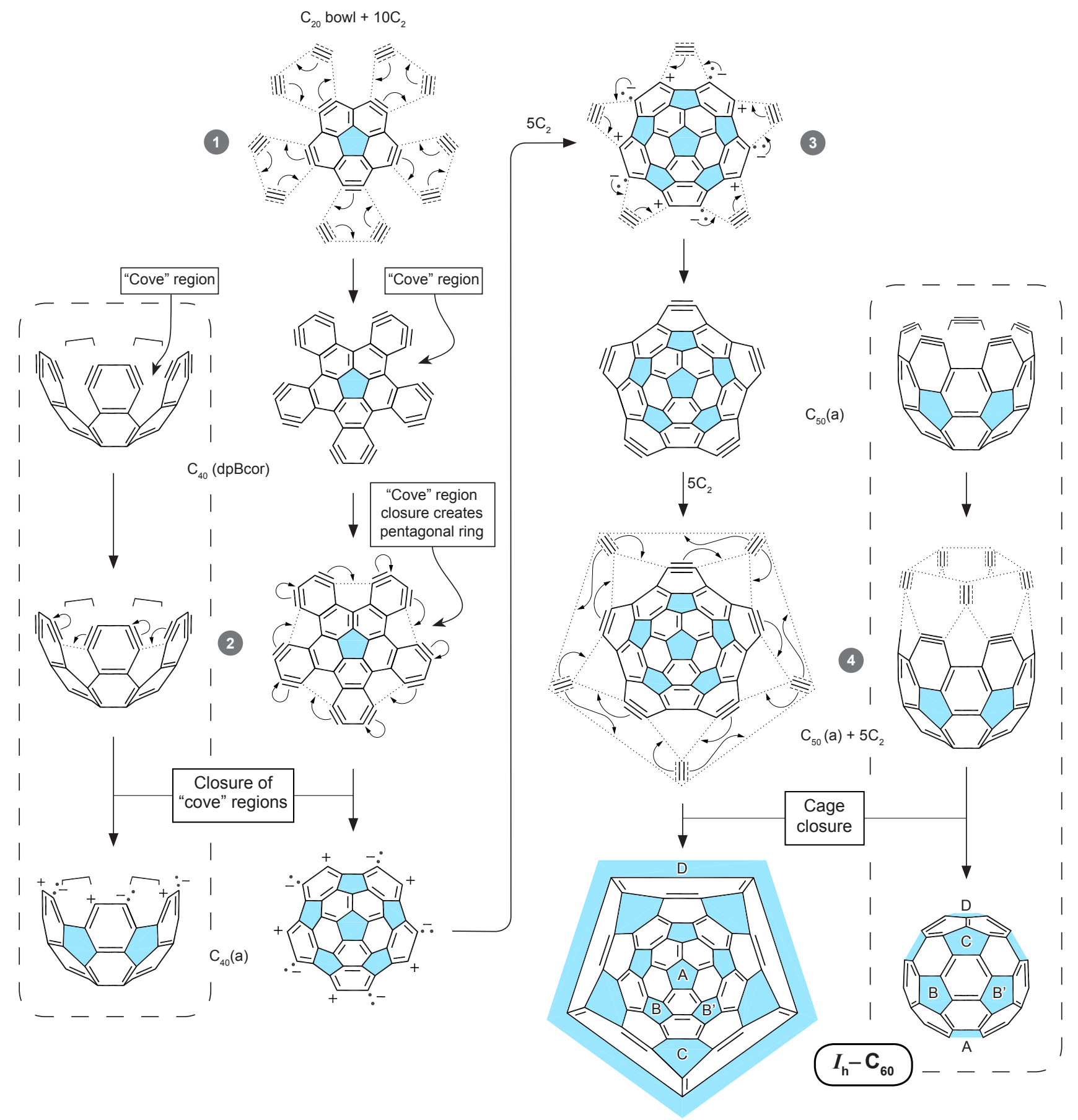

Scheme 3. Proposed growth mechanism for the formation, via sequential addition of $C_{2}$ dimers, of the $I_{h}-C_{60}$ fullerene starting from the $C_{20}$ bowl cluster. See Section 5.2 for the details of the growth sequence. See Scheme 2 for the formation of the $C_{20}$ bowl cluster. (3D depictions are simplified for clarity.) 
non-adjacent pentagonal rings. Subsequent $\mathrm{C}-\mathrm{C}$ bonding between pairs of the interacting $\mathrm{C}_{2}$ units produce five benzenoids rings and consequently form the $12^{\text {th }}$ pentagonal ring, which is depicted as the shaded region at the periphery of the Schlegel projection shown in Scheme 3. The cage closure event can also be visualized as a five-fold $[2+2+2]$ cycloaddition process during which each of the two reactive bonds of each of the five interacting $\mathrm{C}_{2}$ dimers participate in cycloaddition reactions. This ultimately gives rise to the soccer-ball shaped $\mathrm{C}_{60}$ buckminsterfullerene $I_{\mathrm{h}}-\mathrm{C}_{60}$.

\subsection{Why the 12 Pentagons in $I_{\mathrm{h}}-\mathrm{C}_{60}$ are Isolated}

In the $I_{\mathrm{h}}-\mathrm{C}_{60}$ fullerene, each of the 12 pentagons is surrounded by five hexagons and, as such, they are isolated. To explain why the pentagons are isolated has been a subject of debate among several authors. For example, Kroto $^{[36]}$ postulated that within the network of $\sigma$ bonds, "strain-related instability" was minimal for cages with non-adjacent pentagons, but increased with pairs of adjacent pentagons. He termed this the "isolatedpentagon rule" (IPR). Schmaltz et al., ${ }^{[37]}$ focusing on the diminution of $\pi$ bond interaction by adjacent pentagons, suggested that adjacent pentagons had "eight-cycles," in violation of the Hückel's $4 n+2$ rule. Schein and Friedrich $^{[38]}$ suggested that self-assembly that obeys the IPR may be explained by what they called the "head-to-tail exclusion rule," which is a geometric constraint.

It is our view that the growth sequences proposed in this section account for the observed non-adjacency of the twelve pentagonal rings in the $I_{\mathrm{h}}-\mathrm{C}_{60}$ fullerene. As illustrated in Schemes 2 and 3, the reason that these pentagonal rings are isolated is merely the consequence of being created, from beginning to end, between hexagonal rings after "cove" region closures (Scheme 2, Step A3, and Scheme 3, Step 2) or as the result of a cage closure event occurring when five $\mathrm{C}_{2}$ dimers interact with the five bay regions harbored by the $\mathrm{C}_{50}$ (a) cluster such that during these interactions the direction of each $\mathrm{C}_{2}$ dimer is perpendicular to middle bond the bay region it is facing. This cage closure process results in the formation of five new non-adjacent pentagonal rings, and the $12^{\text {th }}$ pentagonal ring, which is isolated by five hexagonal rings (see Scheme 3, Step 3).

\section{Proposed Routes to $D_{5 \mathrm{~h}}-C_{70}$}

Although a variety of routes to $D_{5 \mathrm{~h}}-\mathrm{C}_{70}$ may be envisioned, two suggested growth routes that involve stepwise additions of $\mathrm{C}_{2}$ units, labeled "Route A" and "Route B," are offered in this section and depicted in Scheme 4.

\subsection{Route A: From $\mathrm{C}_{50}(\mathrm{a})$ to $D_{5 \mathrm{~h}}-\mathrm{C}_{70}$}

This growth route begins with the $\mathrm{C}_{50}(\mathrm{a})$ cluster, the proposed formation of which was discussed in Section 5.3. The steps of Route A follow:

Step A1: Five $\mathrm{C}_{2}$ dimers interact via [4+2] cycloaddition processes with the five bay regions harbored by the $\mathrm{C}_{50}$ (a) cluster. Here, the direction of each interacting $\mathrm{C}_{2}$ dimer is parallel to middle bond of the bay it is facing. This leads to the formation of a cluster labeled $\mathrm{C}_{60}(\mathrm{a})$ that features five hexagonal rings at its periphery with each ring having the structure of a cyclohexyne unit. It is important to note that when the five interacting $\mathrm{C}_{2}$ dimers are oriented perpendicular to the bays (as shown in Scheme 3, Step 4) instead of parallel with them, as they are in this step, it results in a cage closure event that yields $I_{\mathrm{h}}-\mathrm{C}_{60}$ and consequently ends the growth process.

Step A2: Five $\mathrm{C}_{2}$ dimers interact with the five bay regions harbored by the $\mathrm{C}_{60}$ (a) cluster such that during these interactions the direction of each $\mathrm{C}_{2}$ dimer is perpendicular to middle bond the bay region it is facing. This results in a cage closure that is identical to the proposed cage closure that yields $I_{\mathrm{h}}-\mathrm{C}_{60}$ from $\mathrm{C}_{50}(\mathrm{a})$ as shown in Scheme 3, Step 4. This process creates: 1) five new benzenoids rings; 2) five new non-adjacent pentagonal rings where each of the rings contains one double bond, and; 3 ) the $12^{\text {th }}$ pentagonal ring, which is depicted as the shaded region at the periphery of the Schlegel projection in Scheme 4. The cage closure event can also be visualized as a five-fold $[2+2+2]$ cycloaddition process during which each of the two reactive bonds of each of the five interacting $\mathrm{C}_{2}$ dimers participate in cycloaddition reactions. This ultimately results in the formation of the $D_{5 \mathrm{~h}}-\mathrm{C}_{70}$ fullerene.

A Schlegel and a schematic $3 \mathrm{D}$ depiction of $\mathrm{C}_{70}$ are shown in Scheme 4. Note that two resonance structures are required to properly represent $\mathrm{C}_{70}$. These twin 2D and 3D depictions are based on data reported by Meier et al. ${ }^{[39]}$ that show evidence of bond delocalization that takes place within the five equatorial hexagonal rings.

\subsection{Route B: From $C_{20}$ Bowl to $D_{5 h}-C_{70}$}

This growth route begins with the $\mathrm{C}_{20}$ bowl cluster, the proposed formation of which was discussed in a Section 4. The steps of Route B follow:

Step B1: Five $\mathrm{C}_{2}$ dimers interact in cycloaddition processes with the five zig-zag edge regions harbored by the $\mathrm{C}_{20}$ bowl cluster. This leads to the formation of a bowl-shaped cluster labeled $\mathrm{C}_{30}(\mathrm{~b})$ that has the carbon skeleton of pentacyclopentacorannulene. This cluster features five pentagonal rings at its periphery, each ring having the structure of a cyclopentyne unit.

Step B2: Each "triple bond" of a cyclopentyne unit is involved in a $[2+2+2]$ cycloaddition process with two $\mathrm{C}_{2}$ dimers. This produces a bowlshaped cluster labeled $\mathrm{C}_{50}(\mathrm{~b})$. The formation of $\mathrm{C}_{50}(\mathrm{~b})$ can be regarded as occurring in two stages: 1) formation of a bowl-shaped intermediate containing five new hexagonal rings with each ring having two "triple bonds," and; 2) the subsequent formation of five other new hexagonal rings as the result of closures of "fjord" regions (6C bays) that exist between newly formed "triple bonds." This closure process is favored because it involves interactions between adjacent "triple bonds" that due to the bowl-shaped geometry of the intermediate are located in very close proximity to each other.

Step B3: The newly created $\mathrm{C}_{50}$ (b) cluster harbors five bay regions exhibiting a zwitterionic character. Five $\mathrm{C}_{2}$ dimers interact via [4+2] cycloaddition processes with the five bay regions. This leads to the formation of the $\mathrm{C}_{60}(\mathrm{~b})$ cluster.

Step B4: Five $\mathrm{C}_{2}$ dimers interact with the five bay region harbored by the $\mathrm{C}_{60}$ (b) cluster in such a way that the orientation of each $\mathrm{C}_{2}$ dimer is perpendicular to middle bond of the bay region it is facing. This results in a cage closure which is similar to the proposed cage closure that creates $I_{\mathrm{h}}-\mathrm{C}_{60}$ from $\mathrm{C}_{50}(\mathrm{a})$, and the one that creates $D_{5 \mathrm{~h}}-\mathrm{C}_{70}$ from $\mathrm{C}_{60}(\mathrm{a})$. In the process, this creates: 1) five new benzenoids rings; 2) five new nonadjacent pentagonal rings where each of the rings contains only single bonds, and; 3 ) the $12^{\text {th }}$ pentagonal ring (depicted as the shaded region at the periphery of the Schlegel projection of Scheme 4) that results from $\mathrm{C}-\mathrm{C}$ bonding between the five interacting $\mathrm{C}_{2}$ units. This cage closure event leads to the $D_{5 \mathrm{~h}}-\mathrm{C}_{70}$ fullerene. A Schlegel and a schematic 3D depiction of $\mathrm{C}_{70}$ are shown in Scheme 4. Note, as previously mentioned, two VB structures are required to properly represent $\mathrm{C}_{70}$. These twin $2 \mathrm{D}$ and $3 \mathrm{D}$ depictions are based on data reported by Meier et al., ${ }^{[39]}$ that show evidence of bond delocalization that takes place within the five equatorial hexagonal rings. 
a
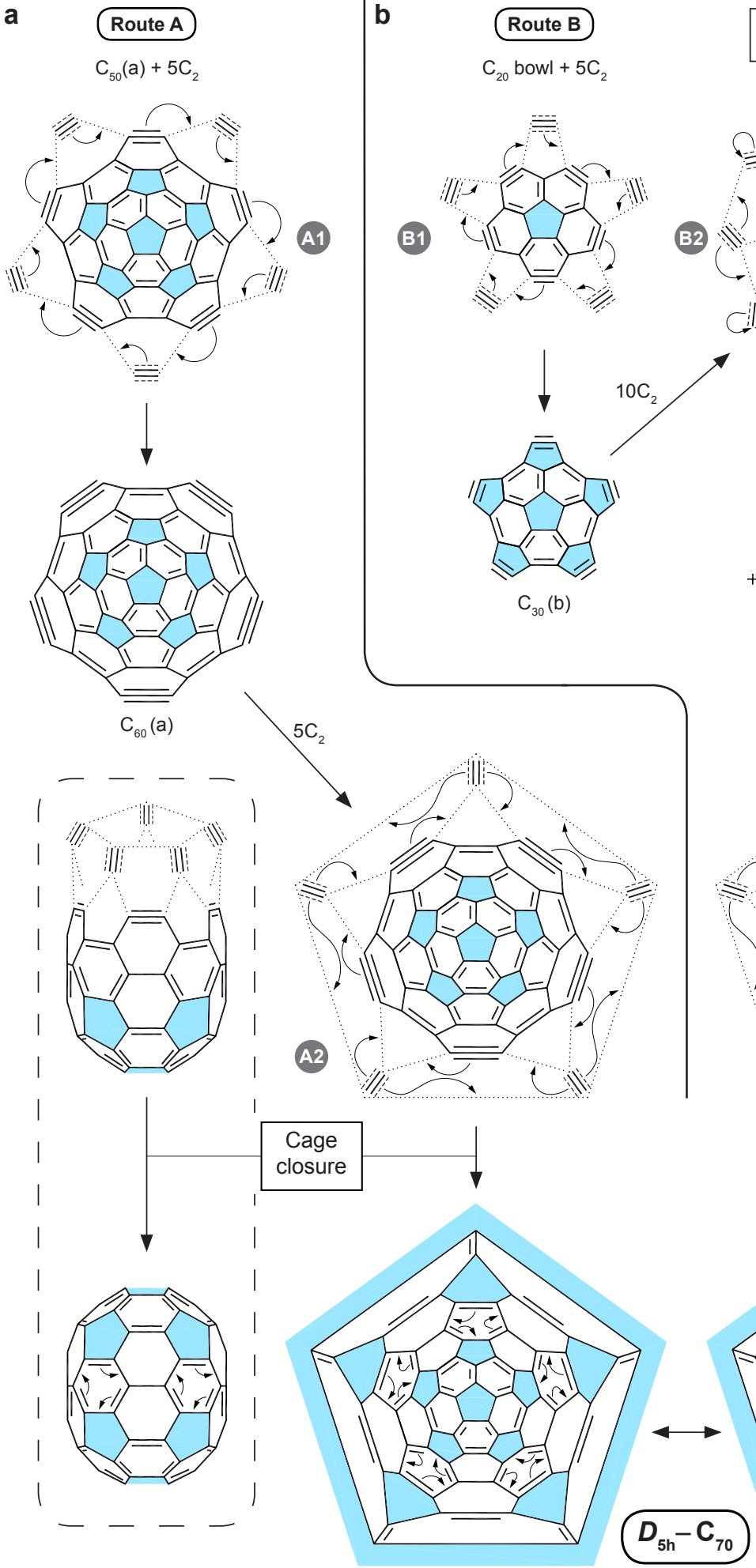

Schlegel projection (A)

B1

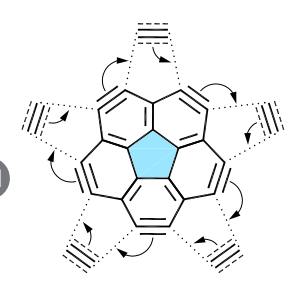

B2)

$\mathrm{C}_{30}$ (b)

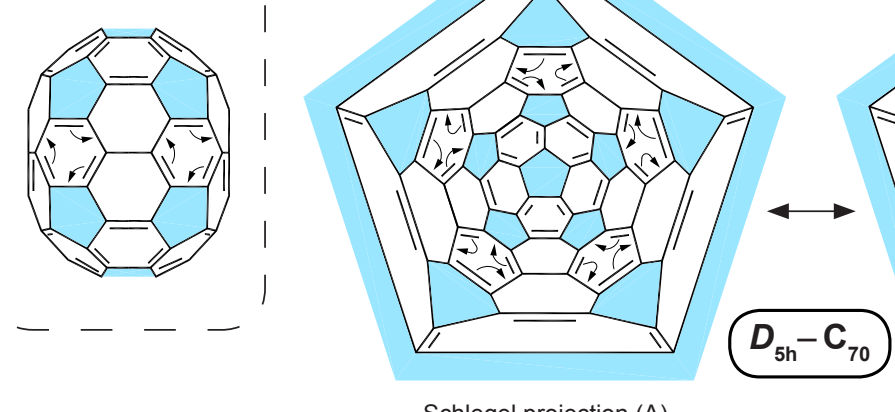

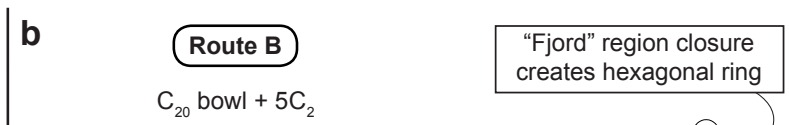

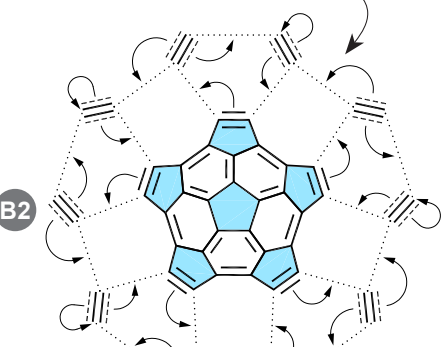

B3
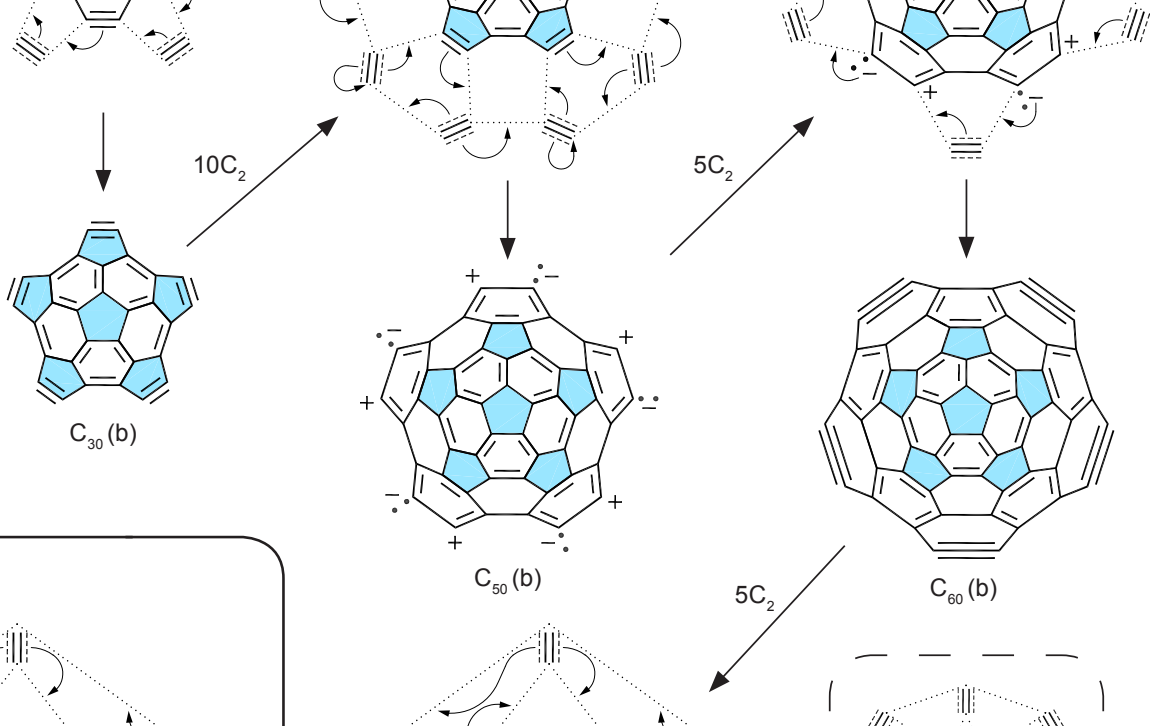

$5 \mathrm{C}_{2}$
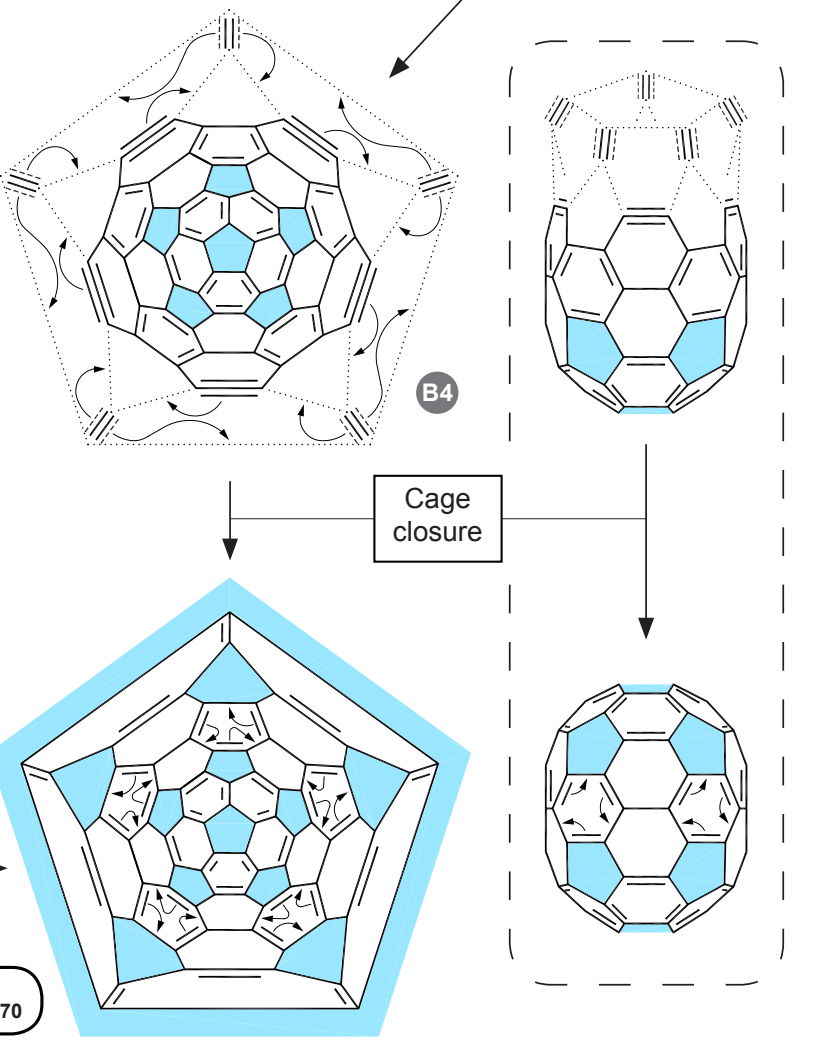

Schlegel projection (B)

Scheme 4. Two proposed growth mechanisms for the formation, via sequential addition of $C_{2}$ dimers, of the $D_{5 h}-C_{70}$ fullerene: Route $A$ begins with the $C_{50}(a)$ cluster. Route $B$ begins with the $C_{20}$ bowl cluster. The detailed growth sequence for Route A is discussed in Section 6.1.1. Route B is discussed in Section 6.1.2. See Scheme 3 for the formation of $C_{50}(a)$, and Scheme 2 for the formation of the $C_{20}$ bowl. (3D depictions are simplified for clarity.) 


\subsection{Why the 12 Pentagons in $D_{5 \mathrm{~h}}-\mathrm{C}_{70}$ are Isolated}

It is our view that the growth sequences proposed in this section can account for the observed non-adjacency of the twelve pentagonal rings of $\mathrm{D}_{5 \mathrm{~h}}-\mathrm{C}_{70}$. To elaborate, let us consider again how these pentagonal rings are created during the proposed growth routes $\mathrm{A}$ and $\mathrm{B}$.

Route A: This route starts with the $\mathrm{C}_{50}$ (a) cluster that contains six pentagonal rings. These rings are isolated because they have been created between hexagonal rings as the result of "cove" region closures (see Schemes 2 and 3). Route A ends with a cage closure event occurring when five $\mathrm{C}_{2}$ dimers interact with the five bay regions harbored by the $\mathrm{C}_{60}$ (a) cluster such that during these interactions the direction of each $\mathrm{C}_{2}$ dimer is perpendicular to middle bond the bay region it is facing. This cage closure process results in the formation of five new non-adjacent pentagonal rings and the $12^{\text {th }}$ pentagonal ring, which is isolated by five hexagonal rings (see Scheme 4, Step A2).

Route B: This route starts with the formation of the $\mathrm{C}_{20}$ bowl cluster that contains one pentagonal ring surrounded by five hexagonal rings. As suggested in Section 4, the pentagonal ring could be produced as the result of a "cove" region closure (see Scheme 2, Step A3) or as the result of addition of the $\mathrm{C}_{6}(\mathrm{~dB})$ cluster to the zig-zag region of the $\mathrm{C}(\mathrm{dNap})$ cluster (see Scheme 2, Step B1). Addition of $\mathrm{C}_{2}$ dimers to the five non-adjacent zig-zag regions of the $\mathrm{C}_{20}$ bowl cluster, depicted in Step B1 of Scheme 4 , leads to the formation of five new non-adjacent pentagonal rings as a result of ring closure. At the end of Step B2 of Scheme 4, each pentagonal ring is surrounded by five hexagonal rings. Route $\mathrm{B}$ ends with a cage closure event occurring when five $\mathrm{C}_{2}$ dimers interact with the five bay regions harbored by the $\mathrm{C}_{60}$ (b) cluster such that during these interactions the direction of each $\mathrm{C}_{2}$ dimer is perpendicular to middle bond the bay region it is facing. As shown in Step B4 of Scheme 4, this cage closure process results in the formation of five new non-adjacent pentagonal rings and the $12^{\text {th }}$ pentagonal ring which is isolated by five hexagonal rings. To summarize, the reason that the twelve pentagonal rings of $D_{5 \mathrm{~h}}-\mathrm{C}_{70}$ are isolated is merely the consequence of them being created between hexagonal rings at the end of growth steps such as ring closure, "cove" closure, or cage closure.

\section{Proposed Routes to Two Isomers of $I_{h}-C_{60}$ Without Stone-Wales Rearrangements}

For decades it was believed that among the 1812 possible topological isomers of the $\mathrm{C}_{60}$ buckminsterfullerene, which is referenced as the ${ }^{\# 1812} \mathrm{C}_{60}$ isomer, the $\mathrm{C}_{60}$ buckminsterfullerene was the only one that could be isolated. However, recently two additional isomers, ${ }^{\# 1809} \mathrm{C}_{60}$ and ${ }^{\# 1804} \mathrm{C}_{60}$, were isolated by Zheng et al. ${ }^{[40]}$ Both were stabilized by chlorination. In this section we focus on the formation mechanisms of these isomers.

\subsection{Route to the ${ }^{\# 1809} \mathrm{C}_{60}$ Isomer}

Let us first consider the ${ }^{\# 1809} \mathrm{C}_{60}$ isomer that exhibits the $C_{2 v}$ symmetry and has two pairs of adjacent pentagons.

Zheng et al ${ }^{[40]}$ produced this isomer as the stabilized chlorinated species ${ }^{\# 1809} \mathrm{C}_{60} \mathrm{Cl}_{8}$. They also produced the bare ${ }^{\# 1809} \mathrm{C}_{60}$ fullerene as the result of dechlorination via thermal spray of ${ }^{\# 1809} \mathrm{C}_{60} \mathrm{Cl}_{8}$ in the gas phase. ${ }^{[41]}$ In a study from 1995, Austin et al. ${ }^{[42]}$ concluded that among the 1812 possible isomers of the icosahedral $I_{\mathrm{h}}-\mathrm{C}_{60}$, the ${ }^{\# 1809} \mathrm{C}_{60}$ isomer, which is also known as the $C_{2 v}-\mathrm{C}_{60}$ isomer, must be the last one to form just before

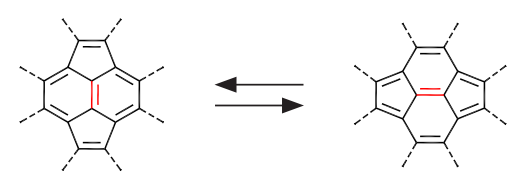

Figure 4. The Stone-Wales (SW) or pyracelene rearrangement was proposed to explain how a pair of hexagons and pentagons could switch places.

the $I_{\mathrm{h}}-\mathrm{C}_{60}$ in any annealing process. According to this study, the $C_{2 v}-\mathrm{C}_{60}$ to $I_{\mathrm{h}}-\mathrm{C}_{60}$ transformation (isomerization) occurs through a mechanism known as the Stone-Wales (SW) rearrangement, also known as the pyracylene rearrangement. ${ }^{[43]}$ This mechanism was first proposed by Stone and Wales in a 1986 paper $^{[43]}$ on possible non-icosahedral isomers of $\mathrm{C}_{60}$, and it was then applied by other researchers to provide a general hypothetical mechanism for interconversion between fullerene isomers.

The SW transformation enables a pair of hexagon and a pair of pentagon to interchange positions. As depicted in Figure 4, it requires an in-plane $90^{\circ}$ rotation of $\mathrm{C}_{2}$ unit. However, let us point out that data tends to show that the possibility of SW transformations actually taking place is very low. For example, studies performed by Marcos et al., ${ }^{[4 a]}$ Scuseria et al., ${ }^{[44 b]}$ and Choi et al. ${ }^{[44]}$ showed that the SW transformation is thermodynamically limited due to a very large activation barrier calculated to be as high as $7-8 \mathrm{eV} \cdot{ }^{[44 b]}$ Let us also point out that no experimental evidence exists that the SW rearrangement actually occurs within the pyracylene molecule. For example, ${ }^{13} \mathrm{C}$ labeling experiments performed by $\mathrm{Scott}^{[45]}$ showed that at temperature up to $1100^{\circ} \mathrm{C}$ the pyracylene molecule does not rearrange according to the Stone-Wales pathway. Similarly, Sarobe et al. ${ }^{[46]}$ reported that at temperatures of $1000^{\circ} \mathrm{C}$ and higher, the pyracylene molecule did not rearrange, but instead it produced a mixture of ethynylacenaphthylenes and yielded acenaphthylene as the result of elimination of $\mathrm{C}_{2}$.

In contrast with the view shared by Zheng et al. ${ }^{[40]}$ and Austin et al., ${ }^{[42]}$ that the ${ }^{\# 1809} \mathrm{C}_{60}$ and ${ }^{\# 1812} \mathrm{C}_{60}$ could be transformed from one to another via Stone-Walles rearrangements, we propose that the formation of the ${ }^{\# 1809} \mathrm{C}_{60}$ isomer can be explained without the need to invoke the hypothetical Stone-Wales rearrangement.

We propose that the $C_{2 v}-\mathrm{C}_{60}$ isomer can be produced as the result of an "imperfect" cage closure event that involves five $\mathrm{C}_{2}$ dimers interacting with the $\mathrm{C}_{50}$ (a) cluster. We have previously suggested that a "perfect" cage closure, which ultimately gives rise to the $I_{\mathrm{h}}-\mathrm{C}_{60}$ fullerene, takes place with the addition of five $\mathrm{C}_{2}$ dimers that are oriented perpendicular to the respective bay regions of the $\mathrm{C}_{50}$ (a) cluster (see Scheme 3, Step 4). However, if one of the five interacting $\mathrm{C}_{2}$ dimers is parallel instead of perpendicular to the bay region it is facing, the $C_{2 v}-\mathrm{C}_{60}$ isomer will be produced. As illustrated in the Schlegel projection shown in Scheme 5a, when this parallel-oriented $\mathrm{C}_{2}$ dimer, labeled $\mathrm{C}_{2}(\mathrm{p})$ (where "( $\mathrm{p}$ )" stands for parallel), interacts with the two "triple bonds" located on each side of the facing bay region and with the perpendicularly-oriented $\mathrm{C}_{2}\left(\mathrm{O}_{1}\right)$ and $\mathrm{C}_{2}\left(\mathrm{O}_{2}\right)$ dimers, (where "(o)" stands for perpendicular), it creates a hexagonal ring as well as two pentagonal rings located on opposite sides of the newly formed hexagonal ring. Additional interactions involving the $\mathrm{C}_{2}\left(\mathrm{o}_{1}\right)$ and $\mathrm{C}_{2}\left(\mathrm{O}_{2}\right)$ dimers, and the two other perpendicular dimers labeled $\mathrm{C}_{2}\left(\mathrm{O}_{3}\right)$ and $\mathrm{C}_{2}\left(\mathrm{O}_{4}\right)$, produce four pentagonal rings as well as three benzenoids rings. The four pentagons, produced as the result of the interactions of the $\mathrm{C}_{2}(\mathrm{p}), \mathrm{C}_{2}\left(\mathrm{o}_{1}\right)$ and $\mathrm{C}_{2}\left(\mathrm{O}_{2}\right)$ dimers, form two pairs of fused pentagons. Ultimately, a $20^{\text {th }}$ hexagonal ring, depicted in Scheme 5 as the shaded 
a

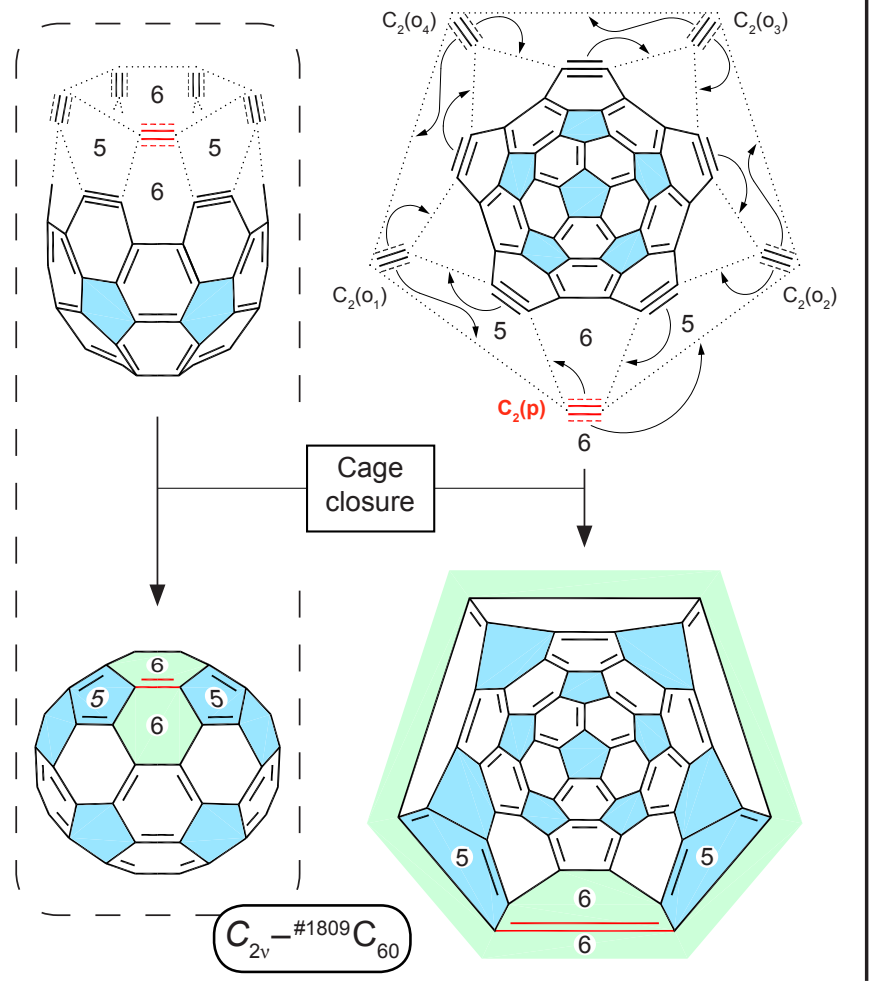

b
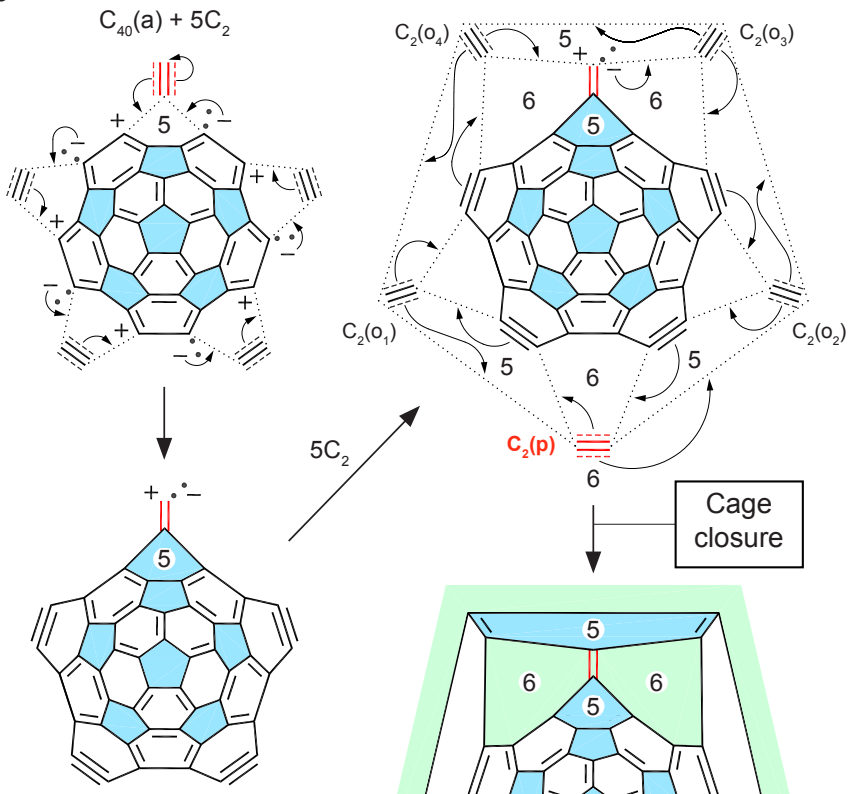

$\mathrm{C}_{50}\left(\mathrm{a}^{\prime}\right)$

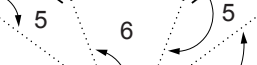

$\mathrm{C}_{2}(\mathrm{p})$

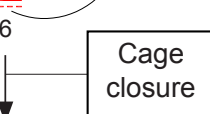
$\mathrm{C}_{2}\left(\mathrm{O}_{2}\right)$

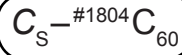

Scheme 5. Proposed routes to two symmetry-breaking isomers of the $I_{\mathrm{h}}-\mathrm{C}_{60}$ fullerene: a) the $C_{2 v}-C_{60}$ isomer, and; b) the $C_{s}-C_{60}$ isomer. As shown in this proposed scheme, these two $\mathrm{C}_{60}$ isomers form simply as the result of "imperfect" growth sequences due to variations in the direction of interacting $\mathrm{C}_{2}$ dimers, and there is therefore no need to invoke the Stone-Wales rearrangement. (3D depictions are simplified for clarity.)

region at the periphery, is created following $\mathrm{C}-\mathrm{C}$ bonding between all the five interacting $\mathrm{C}_{2}$ dimers. The 3D depictions shown in Scheme 5a helps visualize how the $C_{2 v}-\mathrm{C}_{60}$ isomer is produced as the result of an "imperfect" cage closure.

\subsection{Route to the ${ }^{\# 1804} \mathrm{C}_{60}$ Isomer}

Let us now consider the ${ }^{\# 1804} \mathrm{C}_{60}$ isomer that exhibits the $C_{\mathrm{s}}$ symmetry and contains three fused pentagon pairs. Along with the $C_{2 v}-\mathrm{C}_{60}{ }^{\# 1809} \mathrm{C}_{60}$ isomer, Zheng et al. ${ }^{[40]}$ produced the $C_{\mathrm{s}}-\mathrm{C}_{60}$ isomer ${ }^{\# 1804} \mathrm{C}_{60}$, which was stabilized as the chlorinated species ${ }^{\# 1804} \mathrm{C}_{60} \mathrm{Cl}_{12}$. To explain how the ${ }^{\# 1804} \mathrm{C}_{60}$ isomer could be produced, the authors suggested that ${ }^{\# 1809} \mathrm{C}_{60}$ and ${ }^{\# 1804} \mathrm{C}_{60}$ isomers possibly transform from one to another through the $\mathrm{SW}$ rearrangements.

In our view, the formation of the ${ }^{\# 1804} \mathrm{C}_{60}$ isomer can also be explained by a growth pathway that does not involve the SW rearrangement. Our proposed route to the ${ }^{\# 1804} \mathrm{C}_{60}$ isomer is depicted in Scheme $5 \mathrm{~b}$ :

Step 1: This involves a series of cycloadditions between the $\mathrm{C}_{40}$ (a) cluster and five $\mathrm{C}_{2}$ dimers such that four $\mathrm{C}_{2}$ dimers are parallel to the bay regions they are facing while the fifth $\mathrm{C}_{2}$ dimer is perpendicular to the bay region it is facing. Cycloaddition processes involving the four parallel $\mathrm{C}_{2}$ dimers create four hexagonal rings with each having the structure of a benzyne ring while the cycloaddition reaction with the perpendicular $\mathrm{C}_{2}$ dimer creates a cyclopentadienylidene carbene unit that consists of a pentagonal ring attached to an exocylic double bond exhibiting a carbenic character at its end. The newly formed pentagonal ring becomes fused with an existing pentagonal ring that was adjacent to the bay region facing the perpendicular $\mathrm{C}_{2}$ dimer. These interactions by the five $\mathrm{C}_{2}$ dimers give rise to a cluster labeled $\mathrm{C}_{50}\left(\mathrm{a}^{\prime}\right)$.

Step 2: This step corresponds to a cage closure event that is similar to the cage closure event that produces the $C_{5}-\mathrm{C}_{60}$ isomer as depicted in Scheme $5 \mathrm{a}$. This takes place when five $\mathrm{C}_{2}$ dimers interact at the periphery of the $\mathrm{C}_{50}\left(\mathrm{a}^{\prime}\right)$ cluster. Here, four dimers labeled $\mathrm{C}_{2}\left(\mathrm{O}_{1}\right), \mathrm{C}_{2}\left(\mathrm{O}_{2}\right), \mathrm{C}_{2}\left(\mathrm{O}_{3}\right)$ and $\mathrm{C}_{2}\left(\mathrm{O}_{4}\right)$ are each perpendicular to the bay regions that they are facing while one $\mathrm{C}_{2}$ dimer, labeled $\mathrm{C}_{2}(\mathrm{p})$, is parallel to the bay region it is facing. Interactions of the $\mathrm{C}_{2}\left(\mathrm{O}_{3}\right)$ and $\mathrm{C}_{2}\left(\mathrm{O}_{4}\right)$ dimers with the carbenic end of cyclopentadienylidene unit, and also with the two "triple bonds" located at each side of this unit, create two hexagonal rings and one pentagonal ring. On the opposite side of the $\mathrm{C}_{50}\left(\mathrm{a}^{\prime}\right)$ cluster, similar to what we proposed in Section 7.1 to explain the formation of the $C_{2 v}-\mathrm{C}_{60}$ isomer, the parallel $\mathrm{C}_{2}$ (p) dimer interacts with the two "triple bonds" located on each side of the facing bay region and also interacts with the $\mathrm{C}_{2}\left(\mathrm{o}_{1}\right)$ and $\mathrm{C}_{2}\left(\mathrm{o}_{2}\right)$ dimers. This creates a hexagonal ring as well as two pentagonal rings that form on opposite sides of the newly formed hexagonal ring. Additional interactions involving the $\mathrm{C}_{2}\left(\mathrm{o}_{1}\right), \mathrm{C}_{2}\left(\mathrm{O}_{2}\right), \mathrm{C}_{2}\left(\mathrm{O}_{3}\right)$ and $\mathrm{C}_{2}\left(\mathrm{O}_{4}\right)$ dimers creates two benzenoid and two pentagonal rings. Ultimately, a $20^{\text {th }}$ hexagonal ring, depicted in Scheme $5 \mathrm{~b}$ as the shaded region at the periphery, is created following $\mathrm{C}-\mathrm{C}$ bonding between all the five interacting $\mathrm{C}_{2}$ dimers. The Schlegel depiction of the $\mathrm{C}_{\mathrm{s}}-\mathrm{C}_{60}$ isomer that contains three fused-pentagon pairs is shown in Scheme 5b.

The growth sequences proposed in this section to explain the formation of two $I_{\mathrm{h}}$-symmetry-breaking $\mathrm{C}_{60}$ isomers could be generalized to explain 


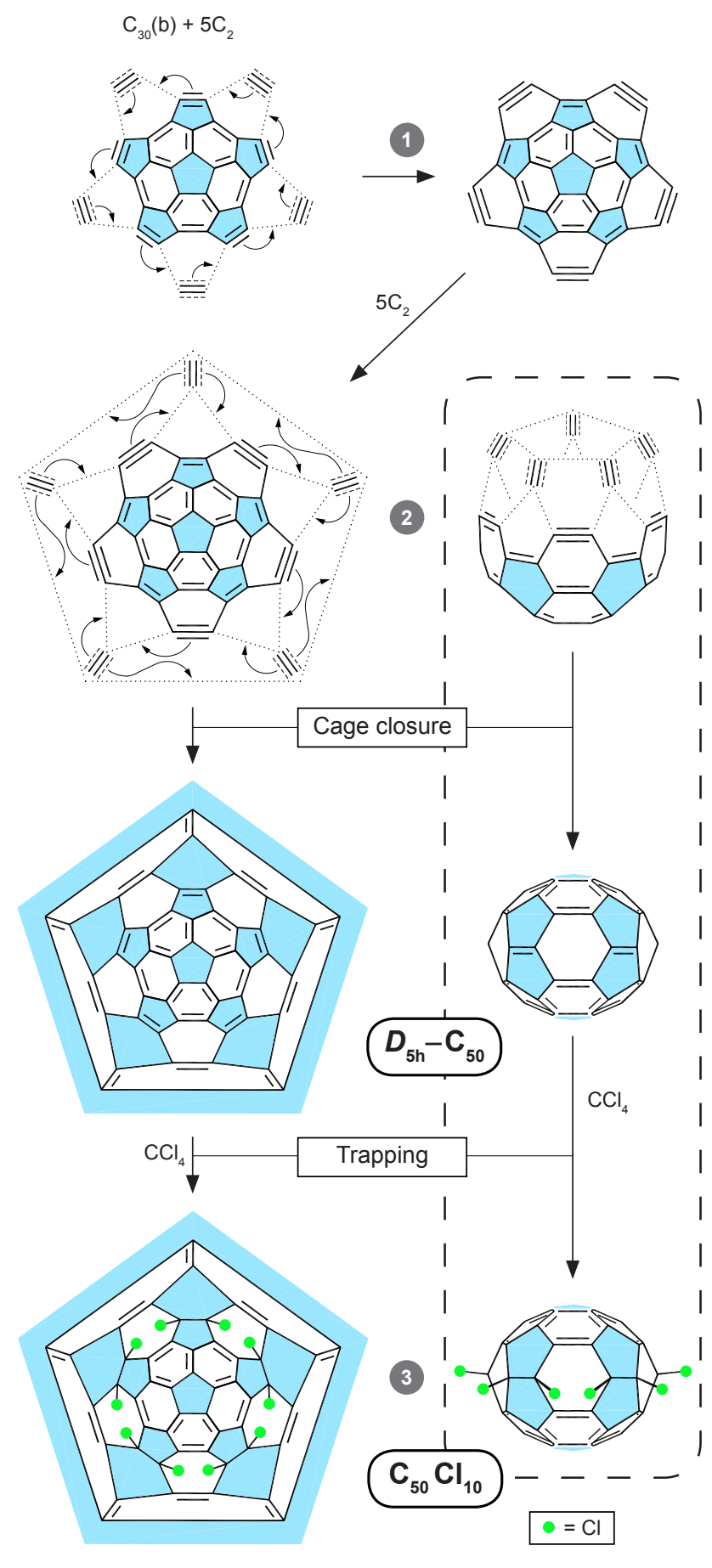

Scheme 6. Proposed route, involving sequential addition of $\mathrm{C}_{2}$ dimers, of the $D_{5 \mathrm{~h}}-\mathrm{C}_{50}$ fullerene trapped by chlorination. See Section 8 for the detailed growth sequence that begins with the $C_{30}$ (b) cluster. See Route $B$ of Scheme 4 for the formation of $\mathrm{C}_{30}$ (b). (3D depictions are simplified for clarity.) how isomers of a specific fullerene may form as the result of "imperfect" growth sequences due to variations in the direction of interacting $\mathrm{C}_{2}$ dimers. To reiterate, our proposed growth sequences renders unnecessary the need to invoke the Stone-Wales rearrangement to explain fullerene isomerization.

\section{Proposed Route to $D_{5 \mathrm{~h}}-\mathrm{C}_{50}$}

Zheng et al. ${ }^{[47]}$ reported the synthesis of a small non-IPR fullerene $\mathrm{C}_{50}$, "a long-sought little sister of $\mathrm{C}_{60}$ " This fullerene, labeled $D_{5 \mathrm{~h}}-\mathrm{C}_{50}$, was captured as $\mathrm{C}_{50} \mathrm{Cl}_{10}$, a chlorofullerene, which is a Saturn-like molecule constructed symmetrically from five pairs of two fused pentagons whose fused edges are covalently bonded by 10 chlorines. ${ }^{[48]}$ The $D_{5 \mathrm{~h}}-\mathrm{C}_{50}$ fullerene was also captured by hydrogenation as the hydrofullerene $\mathrm{C}_{50} \mathrm{H}_{10}{ }^{[49]}$

Our proposed growth route to $D_{5 \mathrm{~h}}-\mathrm{C}_{50}$ is illustrated in Scheme 6. This route starts with the $\mathrm{C}_{30}$ (b) cluster the formation of which was described in Section 6 and depicted in Scheme 4, Step B1. As shown in Scheme 6, Step 1, this cluster harbors five bay regions. Addition of one $\mathrm{C}_{2}$ dimer to each bay region creates five new hexagonal rings with each ring containing a double as well as a "triple bond." This gives rise to the $\mathrm{C}_{40}(\mathrm{~b})$ cluster that features at its periphery five bay regions that are separated by five "triple bonds." At Step 2, cage closure takes place when the $\mathrm{C}_{40}$ (b) cluster interacts with five $\mathrm{C}_{2}$ dimers. In this process, the direction of each $\mathrm{C}_{2}$ dimer is perpendicular to middle bond of the bay region it is facing. This is similar to the proposed cage closure event that creates $I_{\mathrm{h}}-\mathrm{C}_{60}$ from $\mathrm{C}_{50}$ (a) (see Scheme 2, Step 3). Here, each $\mathrm{C}_{2}$ dimer can interact with two "triple bonds" creating five pentagonal rings that become fused to the five pentagonal rings that already exist in the $\mathrm{C}_{40}(\mathrm{~b})$ cluster. Subsequent $\mathrm{C}-\mathrm{C}$ bonding between pairs of the interacting $\mathrm{C}_{2}$ units produce five benzenoid rings and also ultimately creates the $12^{\text {th }}$ pentagonal ring, which is depicted in Scheme 6 as the shaded region at the periphery of the Schlegel projection. The cage closure event gives rise to the $D_{5 \mathrm{~h}}-\mathrm{C}_{50}$ fullerene that, due to the presence of five pairs of fused pentagons, is so highly strained that it could not be found experimentally in its bare form. However, it was stabilized by exhohedral chlorination. As shown in Step 3 , the addition of 10 chlorine atoms to the pentagon-pentagon vertex fusions produced the $D_{5 \mathrm{~h}}-\mathrm{C}_{50} \mathrm{Cl}_{10}$ fullerene. Similarly, addition of $10 \mathrm{H}$ to the pentagon-pentagon vertex fusions, would lead to the formation of the $D_{5 \mathrm{~h}}-\mathrm{C}_{50} \mathrm{H}_{10}$ hydrofullerene.

\section{Proposed PAH Growth Mechanisms During Carbon Arc and Laser Ablation Processes}

The growth sequences proposed in this section involve the initial formations of bare carbon clusters that if hydrogenated will lead to the formation of PAHs, and if chlorinated, will yield chloro-PAHs.

In previous sections, we discussed the formation of bare carbon clusters that may be involved in the growth mechanisms of fullerenes. If hydrogenated, these clusters would lead to the formation of PAHs such as naphthalene, phenanthrene, fluoranthene, benzo[ghi]fluoranthene, and corannulene. In the following subsections, we suggest a series of growth mechanisms that involve the formation of: 1) PAHs via dimerization processes; 2) cyclopenta-fused PAHs (CP-PAHs) via addition of $\mathrm{C}_{2}$ dimers to zig-zag regions, and; 3) PAHs with an odd number of carbon (o-PAHs) via addition of atomic carbon. 
a

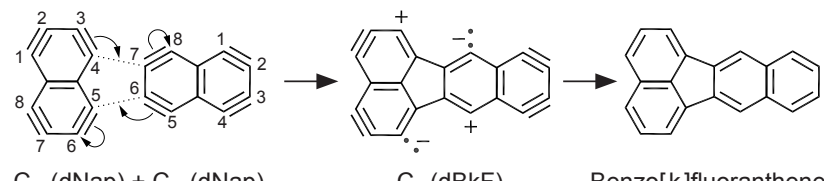
$\mathrm{C}_{10}(\mathrm{dNap})+\mathrm{C}_{10}(\mathrm{dNap}) \quad \mathrm{C}_{20}(\mathrm{dBkF}) \quad$ Benzo[k]fluoranthene b ------------------------

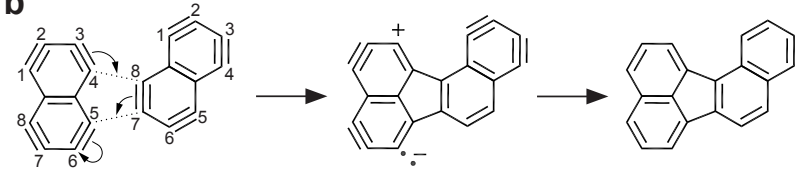
$\mathrm{C}_{10}(\mathrm{dNap})+\mathrm{C}_{10}(\mathrm{dNap}) \quad \mathrm{C}_{20}(\mathrm{dBjF}) \quad$ Benzo[j]fluoranthene

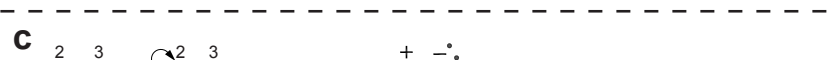

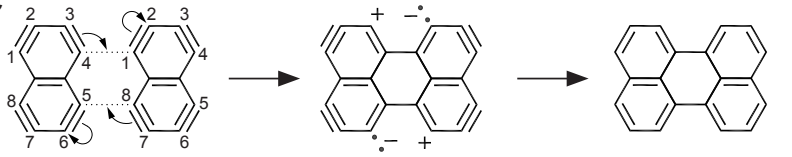

$\mathrm{C}_{10}(\mathrm{dNap})+\mathrm{C}_{10}(\mathrm{dNap}) / \mathrm{C}_{20}(\mathrm{dPer}) \quad$ Perylene

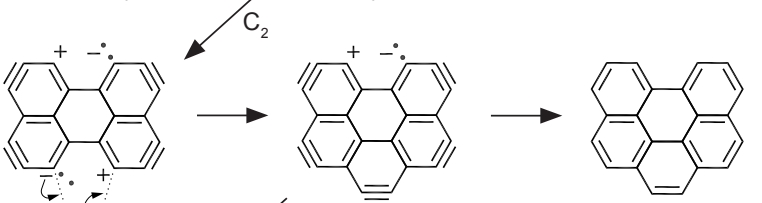

$\mathrm{C}_{2} / \mathrm{C}_{22}$ (dBghiPer) Benzo[ghi]perylene

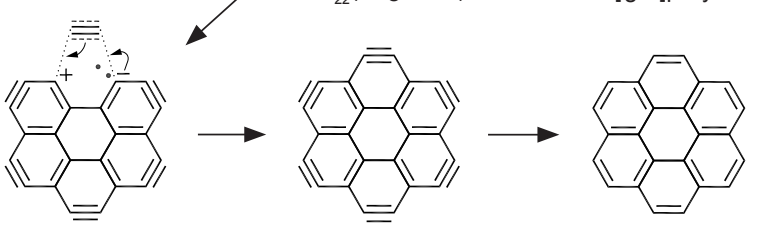
$\mathrm{C}_{24}$ (dCor) Coronene

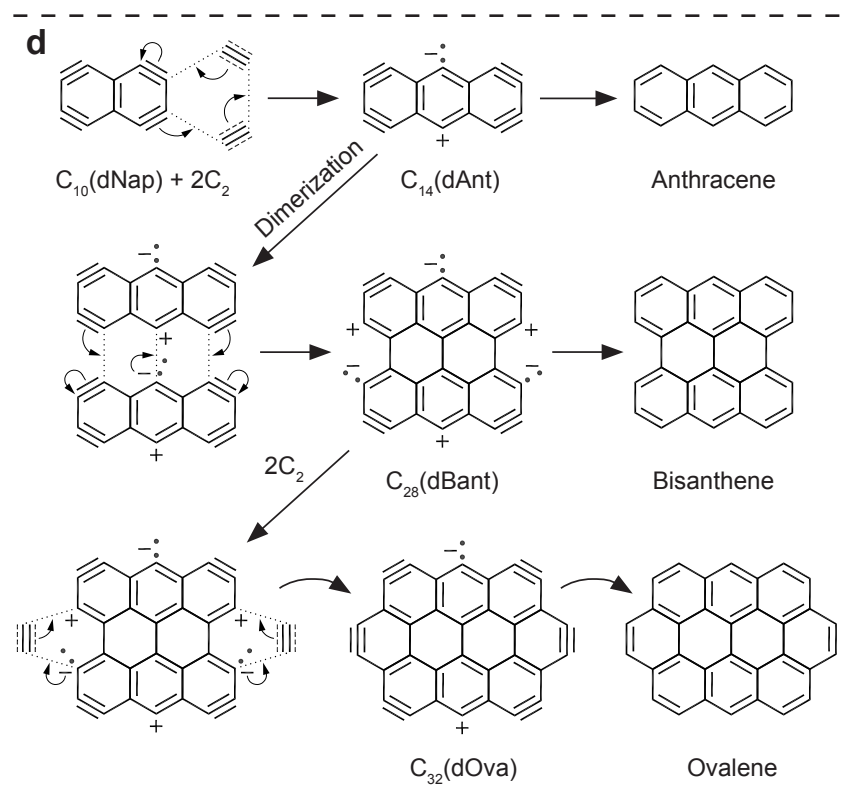

Scheme 7. Proposed growth mechanism to explain how PAHs could form as the result of trapping by hydrogenation of bare carbon clusters that were created via sequential addition of $\mathrm{C}_{2}$ dimers during arc-discharge or laser ablation of graphite.

\subsection{Proposed Routes to PAHs Involving Dimerizations of Carbon Clusters}

The proposed growth routes to PAHs occurring via dimerizations of carbon clusters are depicted in Scheme 7.

Scheme 7a: Two $\mathrm{C}_{10}(\mathrm{dNap})$ clusters combine in such a way that the $\mathrm{C} 3-\mathrm{C} 4$ and $\mathrm{C} 5-\mathrm{C} 6$ "triple bonds" of one $\mathrm{C}_{10}(\mathrm{dNap})$ cluster interact respectively with the $\mathrm{C} 7-\mathrm{C} 8$ and $\mathrm{C} 5-\mathrm{C} 6$ "triple bonds" of the other $\mathrm{C}_{10}$ (dNap) cluster. This process, during which a pentagonal ring is created, produces the $\mathrm{C}_{20}(\mathrm{dBkF})$ cluster, which if hydrogenated would yield benzo[k]fluoranthene.

Scheme 7b: Two $\mathrm{C}_{10}(\mathrm{dNap})$ clusters combine in such a way that the $\mathrm{C} 3-\mathrm{C} 4$ and $\mathrm{C} 5-\mathrm{C} 6$ "triple bonds" of one $\mathrm{C}_{10}$ (dNap) cluster interact with the $\mathrm{C} 7-\mathrm{C} 8$ "triple bond" of the other $\mathrm{C}_{10}(\mathrm{dNap})$ cluster. This process, during which a pentagonal ring is created, produces the $\mathrm{C}_{20}(\mathrm{dBjF})$ cluster, which if hydrogenated would yield benzo[j]fluoranthene.

Scheme $7 \mathrm{c}$ : Two $\mathrm{C}_{10}(\mathrm{dNap})$ clusters combine in such a way that the $\mathrm{C} 3-\mathrm{C} 4$ and $\mathrm{C} 5-\mathrm{C} 6$ "triple bonds" of one $\mathrm{C}_{10}(\mathrm{dNap})$ cluster interact respectively with the $\mathrm{C} 1-\mathrm{C} 2$ and $\mathrm{C} 7-\mathrm{C} 8$ of the other $\mathrm{C}_{10}$ (dNap) cluster. This process, during which a hexagonal ring is created, produces the $\mathrm{C}_{20}(\mathrm{dPer})$ cluster, which if hydrogenated would yield perylene. Addition of one $\mathrm{C}_{2}$ dimer to one of the bay regions harbored by the $\mathrm{C}_{20}(\mathrm{dPer})$ cluster leads to the formation of the $\mathrm{C}_{22}$ (dBghiPer) cluster, which if hydrogenated would yield benzo[ghj]perylene. Addition of one $\mathrm{C}_{2}$ dimer to the bay region of the $\mathrm{C}_{22}$ (dBghiPer) cluster produces the $\mathrm{C}_{24}$ (dCor) cluster, which if hydrogenated would yield coronene.

Scheme 7d: This illustrates a cycloaddition process involving the interaction of two $\mathrm{C}_{2}$ dimers with the $\mathrm{C} 1-\mathrm{C} 2$ and $\mathrm{C} 3-\mathrm{C} 4$ 'triple bonds' of one $\mathrm{C}_{10}(\mathrm{dNap})$ cluster. This process, during which a hexagonal ring is created, produces the $\mathrm{C}_{14}(\mathrm{dAnt})$ cluster, which if hydrogenated would yield anthracene. Interaction between two $\mathrm{C}_{14}(\mathrm{dAnt})$ clusters, involving their zig-zag edge regions, result in a dimerization that produces the $\mathrm{C}_{28}(\mathrm{dbAnt})$ cluster, which if hydrogenated would yield bisanthene. Addition to two $\mathrm{C}_{2}$ dimers, one to each of the two bay regions harbored by the $\mathrm{C}_{28}(\mathrm{dbAnt})$ cluster, produces the $\mathrm{C}_{32}$ (dOva) cluster which features two new hexagonal rings. If hydrogenated, the $\mathrm{C}_{32}(\mathrm{dOva})$ cluster would yield ovalene.

\subsection{Proposed routes to CP-PAHs}

In this section we propose a series of growth sequence that may be responsible for the formation of a selected group of cyclopenta-fused polycyclic aromatic hydrocarbons (CP-PAHs) that have been identified in trapping experiments. These sequences are depicted in Scheme 8:

Scheme 8a: Addition of one $\mathrm{C}_{2}$ dimer to one zig-zag edge region of the $\mathrm{C}_{10}$ (dNap) cluster produces the $\mathrm{C}_{12}(\mathrm{dAcn})$ cluster,

which if hydrogenated would yield acenaphtylene. Addition of one $\mathrm{C}_{2}$ dimer to the zig-zag edge region of the $\mathrm{C}_{12}(\mathrm{dAcn})$ cluster yields the $\mathrm{C}_{14}$ (dPyra) cluster, which if hydrogenated would yield pyracylene. The $\mathrm{C}_{14}$ (dPyra) cluster, features two pentagonal rings at its periphery, each ring having the structure of a cyclopentyne unit. If each "triple bond" of the cyclopentyne units is involved in a $[2+2+2]$ cycloaddition process with two $\mathrm{C}_{2}$ dimers, it would produce the $\mathrm{C}_{22}(\mathrm{dIFlu})$ cluster, which if hydrogenated would yield indeno[1,2,3-cd]fluoranthene.

Scheme 8b: Addition of one $\mathrm{C}_{2}$ dimer to one zig-zag edge region of the $\mathrm{C}_{14}(\mathrm{dPhe})$ cluster produces the $\mathrm{C}_{16}(\mathrm{dAcp})$ cluster, which if hydrogenated would yield acephenanthrylene. Addition of one $\mathrm{C}_{2}$ dimer to the zigzag edge region of the $\mathrm{C}_{16}(\mathrm{dAcp})$ cluster produces the $\mathrm{C}_{18}(\mathrm{dCphiAce})$ cluster, which if hydrogenated, would give rise to cyclopenta[hi]acephenanthrylene. 


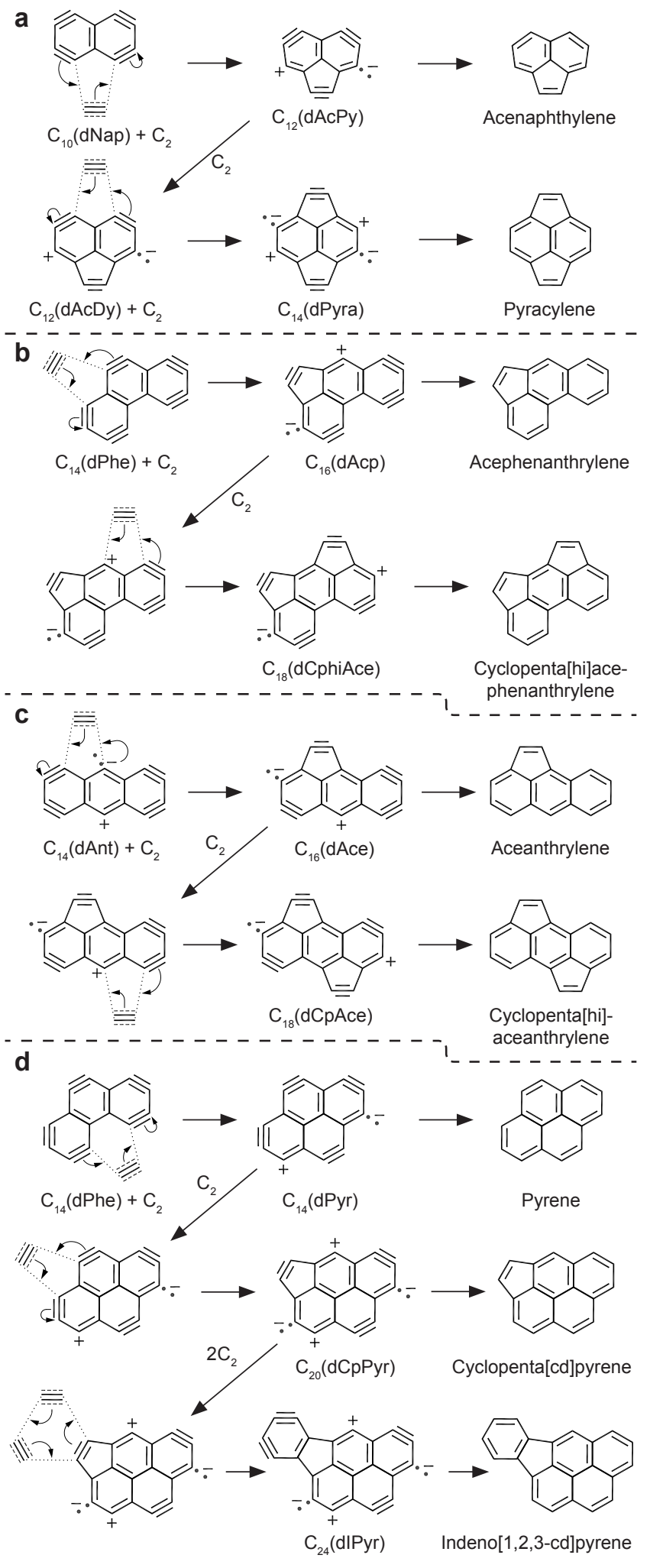

Scheme 8. Proposed growth mechanisms to explain how CP-PAHs could form as the result of trapping by hydrogenation of bare carbon clusters that were created, via sequential addition of $\mathrm{C}_{2}$ dimers, during arc-discharge or laser ablation of graphite.
Scheme 8c: Addition of one $\mathrm{C}_{2}$ dimer to one zig-zag edge region of the $\mathrm{C}_{14}(\mathrm{dAnt})$ cluster produces the $\mathrm{C}_{16}(\mathrm{dAcp})$ cluster, which if hydrogenated would yield aceanthrylene. Addition of one $\mathrm{C}_{2}$ dimer to the zig-zag edge region of the $\mathrm{C}_{16}(\mathrm{dAce})$ cluster produces the $\mathrm{C}_{18}(\mathrm{dCpAce})$ cluster, which if hydrogenated would yield cyclopenta[hi] aceanthrylene.

Scheme 8d: Addition of one $\mathrm{C}_{2}$ dimer to the bay region of the $\mathrm{C}_{14}(\mathrm{dPh})$ cluster produces the $\mathrm{C}_{16}(\mathrm{dPyr})$ cluster, which if hydrogenated would yield pyrene. Addition of one $\mathrm{C}_{2}$ dimer to one zig-zag edge region of the $\mathrm{C}_{16}(\mathrm{dPyr})$ cluster produces the $\mathrm{C}_{18}(\mathrm{dCpAce})$ cluster, which if hydrogenated would yield cyclopenta[hi] aceanthrylene. Note that the $\mathrm{C}_{18}(\mathrm{dCpAce})$ cluster features a cyclopentyne unit. A $[2+2+2]$ cycloaddition process involving the "triple bond" of this cyclopentyne unit and two $\mathrm{C}_{2}$ dimers leads to the formation of the $\mathrm{C}_{22}$ (dIndPyr) cluster, which if hydrogenated would yield indeno[1,2,3-cd]pyrene. Note that the $\mathrm{C}_{22}(\mathrm{dIndPyr})$ cluster could also form as the result of addition of the $\mathrm{C}_{6}(\mathrm{~dB})$ cluster to one zig-zag edge region of the $\mathrm{C}_{16}(\mathrm{dPyr})$ cluster.

\subsection{Proposed Routes to Odd-PAHs}

In this section we propose a series of growth sequence that may be responsible for the formation of a selected group of PAHs that have an odd number of carbon atoms (odd-PAHs). These proposed growth sequences are depicted in Scheme 9:

Scheme 9a: Interaction of one $\mathrm{C}_{2}$ dimer with one "triple bond' of the $\mathrm{C}_{6}(\mathrm{~dB})$ cluster produces the $\mathrm{C}_{8}(\mathrm{dPac})$ cluster, which if hydrogenated would yield phenylacetylene. A [4+1] cycloaddition reaction of the $\mathrm{C}_{8}(\mathrm{dPac})$ cluster with atomic carbon $\mathrm{C}_{1}$ creates a pentagonal ring. This ring closure leads to the formation of the $\mathrm{C}_{9}(\mathrm{dInd})$ cluster, which if hydrogenated would yield indene.

Scheme 9b: Interaction of one $\mathrm{C}_{2}$ dimer with the $\mathrm{C} 1-\mathrm{C} 2$ "triple bond" of the $\mathrm{C}_{10}(\mathrm{dNap})$ cluster produces the $\mathrm{C}_{12}(\mathrm{dE} 1 \mathrm{Nap})$ cluster, which if hydrogenated would yield 1-ethylnylnaphthalene. $\mathrm{A}[5+1]$ cycloaddition reaction of the $\mathrm{C}_{12}(\mathrm{dE} 1 \mathrm{Nap})$ cluster with carbon $\mathrm{C}_{1}$ leads to the formation of the $\mathrm{C}_{13}(\mathrm{dPhn})$ cluster, which if hydrogenated would yield phenalene.

Scheme 9c: Two $\mathrm{C}_{6}(\mathrm{~dB})$ clusters combine with each other to form the $\mathrm{C}_{12}$ (dbPhyl) cluster, which if hydrogenated would yield biphenyl. Starting from the $\mathrm{C}_{12}(\mathrm{dbPhyl})$ cluster, various reactions can take place: 1) intramolecular ring closure leads to the formation of the $\mathrm{C}_{12}(\mathrm{dbPhn})$ cluster, which if hydrogenated would yield biphenylene; 2) addition of atomic carbon $\mathrm{C}_{1}$ to one bay region of the $\mathrm{C}_{12}$ (dbPhyl) cluster leads to the formation of the $\mathrm{C}_{13}(\mathrm{dFlo})$ cluster, which if hydrogenated would yield fluorine, and; 3 ) addition of one $\mathrm{C}_{6}(\mathrm{~dB})$ cluster to one bay region of the $\mathrm{C}_{12}(\mathrm{dbPhyl})$ cluster leads to the formation of the $\mathrm{C}_{18}(\mathrm{dtPhn})$ cluster, which if hydrogenated would yield triphenylene.

Scheme 9d: Addition of atomic carbon $\mathrm{C}_{1}$ to the bay region of the $\mathrm{C}_{14}(\mathrm{dPhe})$ cluster (dehydrogenated phenanthrene) leads to the formation of the $\mathrm{C}_{15}(\mathrm{dBdefF})$ cluster, which if hydrogenated would yield benzo[def] fluorene.

\subsection{Summarizing proposed routes to bare carbon clusters that are presumed precursors of PAHs}

All the growth sequences that we previously proposed illustrate how bare carbon clusters that originate as the result of sequential additions of $\mathrm{C}_{2}$ dimers could be transformed into a variety of larger clusters as long as they remain dehydrogenated. The varioius processes that could be resposible for such transformations are summarized in what follows:

a) Bare carbon clusters could grow to larger clusters as the result of a 
a

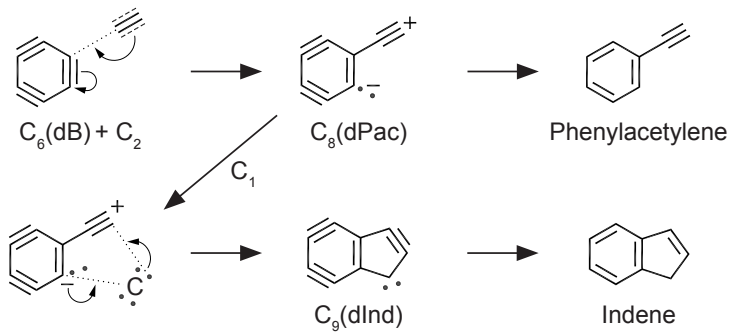

${ }^{-}-$
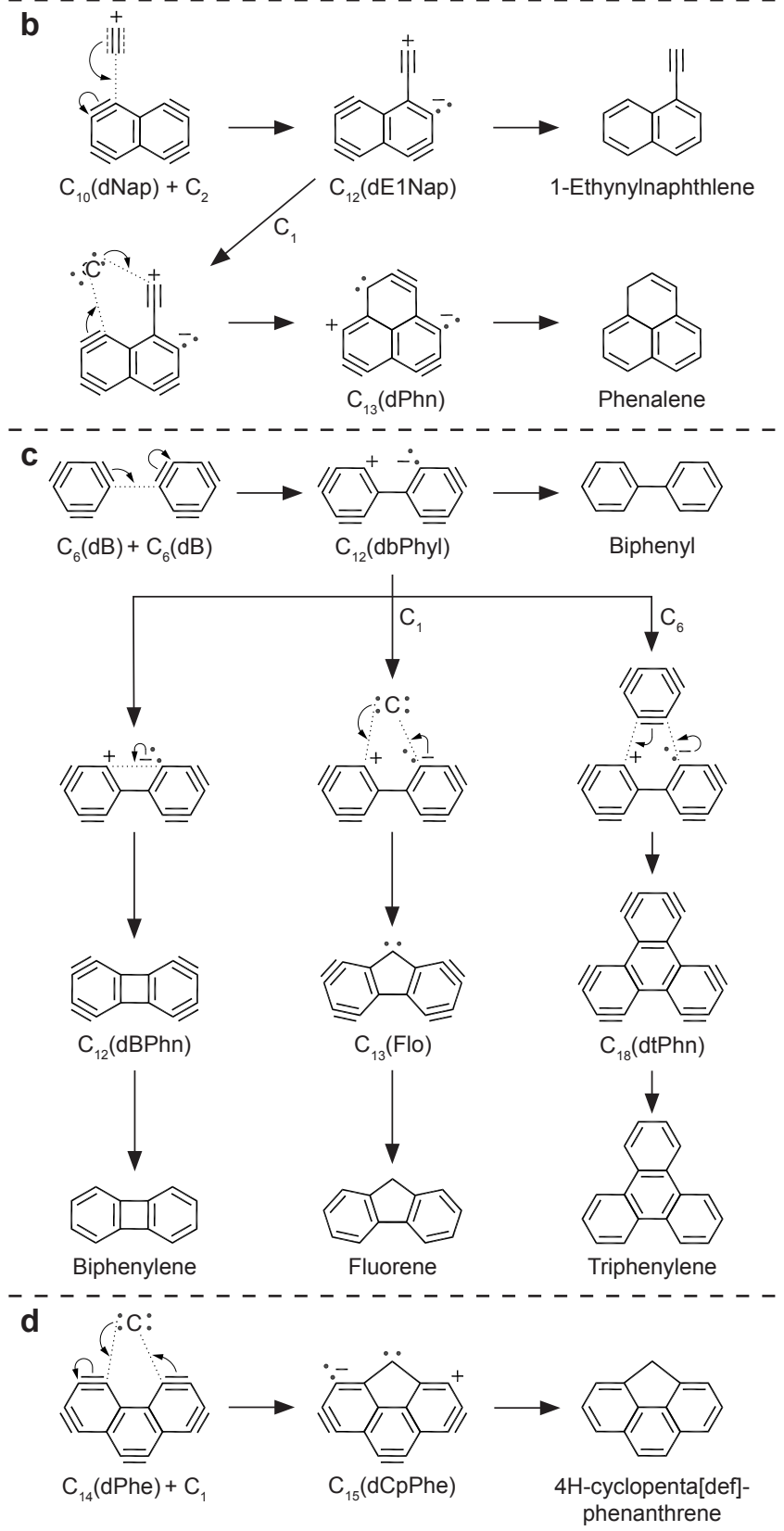

Scheme 9. Proposed growth mechanism to explain how odd-PAHs could form as the result of trapping by hydrogenation of bare carbon clusters that were created, via addition of $\mathrm{C}_{2}$ dimers and atomic carbon $\mathrm{C}_{1}$, during arc-discharge or laser ablation of graphite. cycloaddition reaction involving two $\mathrm{C}_{2}$ dimers interacting at the cluster periphery. For example, we have shown how such a process could lead to the formation of the $\mathrm{C}_{10}(\mathrm{dNap})$ cluster starting from the $\mathrm{C}_{6}(\mathrm{~dB})$ cluster (see Scheme 1, Step 7) and starting from the $\mathrm{C}_{10}(\mathrm{dNap}$ ) cluster this process could lead to the formation of two $\mathrm{C}_{14}$ cluster isomers: the $\mathrm{C}_{14}(\mathrm{dPh})$ cluster that exhibits the carbon skeleton of phenanthrene, (see Scheme 2, Step A1); and the $\mathrm{C}_{14}(\mathrm{dAnt})$ cluster that exhibits the carbon skeleton of anthracene (see Scheme $7 d$ ). Starting from the $\mathrm{C}_{14}(\mathrm{dPhe})$ cluster, continuing this growth process could lead to the formation of four possible $\mathrm{C}_{18}$ cluster isomers (not depicted) that would exhibit the carbon skeletons of chrysene, benz[a]anthracene, benz[c]phenanthrene, and triphenylene.

b) Bare carbon clusters that harbor one or more bay regions could grow as the result of addition of $\mathrm{a}_{2}$ dimer to a bay region. Examples of such process, depicted in Scheme 7, illustrate how addition of $\mathrm{a}_{2}$ dimer to a bay region of the $\mathrm{C}_{20}(\mathrm{dPer})$ leads to the formation of the $\mathrm{C}_{22}$ cluster that exhibits the carbon skeleton of benzo[ghi]perylene, and then how an addition of $\mathrm{a}_{2}$ dimer to the bay region of this $\mathrm{C}_{22}$ cluster creates the $\mathrm{C}_{24}$ (dCor) cluster that exhibits the carbon skeleton of coronene.

c) Bare carbon clusters could interact with each other in dimerization reactions. For example, as depicted in Scheme7a, b, and c, it was shown how the $\mathrm{C}_{20}(\mathrm{dPer}), \mathrm{C}_{20}(\mathrm{dBkF})$ and $\mathrm{C}_{20}(\mathrm{dBjF})$ clusters could be produced from dimerization of $\mathrm{C}_{10}$ (dNap) clusters.

d) The $\mathrm{C}_{6}(\mathrm{~dB})$ cluster could be involved in cycloaddition process with other carbon clusters to produce larger clusters. For example, as depicted in Scheme 2, Step B1, it was shown how the addition of $\mathrm{C}_{6}(\mathrm{~dB})$ to the zig-zag region of $\mathrm{C}_{10}(\mathrm{dNap})$ could produce the $\mathrm{C}_{16}(\mathrm{~dB})$ that exhibits the carbon skeleton of fluoranthene. Similarly, addition of $\mathrm{C}_{6}(\mathrm{~dB})$ to one zigzag region of $\mathrm{C}_{14} \mathrm{~d}(\mathrm{Phe})$ could produce the $\mathrm{C}_{20}(\mathrm{dBbFlu})$ cluster that exhibits the carbon skeleton benzo[b]fluoranthene. The $\mathrm{C}_{6}(\mathrm{~dB})$ cluster could also interact with clusters harboring bay regions. For example, in Scheme $9 \mathrm{c}$ it was shown how addition of the $\mathrm{C}_{6}(\mathrm{~dB})$ cluster to the bay region of the $\mathrm{C}_{12}$ cluster that exhibits the carbon skeleton of diphenyl could produce the $\mathrm{C}_{18}$ cluster that exhibits the carbon skeleton of triphenylene. Similarly, addition of the $\mathrm{C}_{6}(\mathrm{~dB})$ cluster to the bay region of $\mathrm{C}_{14}(\mathrm{dPhe})$ could lead to the formation of the $\mathrm{C}_{20}$ cluster that exhibits the carbon skeleton of benzo[e]pyrene (not depicted).

e) Addition of $\mathrm{C}_{2}$ dimers to bare carbon clusters that contain zig-zag regions could produce clusters having pentagonal rings at their periphery. For example, as depicted in Scheme 8, it was shown how addition of one $\mathrm{C}_{2}$ dimer to one zig-zag region of $\mathrm{C}_{10}(\mathrm{dNap})$ could produce the $\mathrm{C}_{12}(\mathrm{dAcPy})$ cluster that exhibits the carbon skeleton of acenaphtylene, and how addition of one $\mathrm{C}_{2}$ dimer to the zig-zag region of $\mathrm{C}_{12}(\mathrm{dAcPy})$ could produce the $\mathrm{C}_{14}(\mathrm{dPyr})$ cluster that exhibits the carbon skeleton of pyracylene.

f) Bare carbon clusters could react with atomic carbon to produce clusters exhibiting the carbon skeleton of odd-PAHs. For example, as depicted in Scheme 9, it was shown how the reaction of atomic carbon with the $\mathrm{C}_{8}(\mathrm{dPac})$ cluster that exhibits the carbon skeleton of phenylacetylene could produce the $\mathrm{C}_{9}(\mathrm{dInd})$ cluster that exhibits the carbon skeleton of indene, and how addition of atomic carbon to the bay region of the $\mathrm{C}_{12}$ cluster that exhibits the carbon skeleton of diphenyl could lead to the formation of the $\mathrm{C}_{13}$ cluster that exhibits the carbon skeleton of fluorene.

g) Addition of one $\mathrm{C}_{2}$ dimer to one position of a bare carbon cluster could produce a cluster having a $\mathrm{C}_{2}$ substituent attached at its edge. For example, as depicted in Scheme 9, it was shown how such process could lead to the formation of the $\mathrm{C}_{8}$ and $\mathrm{C}_{12}$ clusters that exhibit the carbon skeletons of phenylacetylene and ethynyl naphthalene, respectively.

h) Hydrogenation of bare clusters would yield different classes of PAHs: 1) peri- and cata-condensed PAHs such as phenanthrene, pyrene, coronene and ovalene; 2) cyclo-pentafused PAHs such as acenaphtylene, acephenanthrylene and cyclopenta[cd]pyrene; 3) ethynyl-PAHs such as 
phenylacetylene, styrene, 1- and 2-ethynylnahphtalenes, and; 4) oddPAHs such as indene, phenalene, fluorene, cyclopenta[def]phenanthrene).

\section{PAH and Fullerene Formation Mechanisms in Combustion Systems and the ISM}

In previous sections we proposed a series of growth sequences to explain the formation of fullerenes and PAHs in processes that involve arc discharge ablation of graphite electrodes or laser vaporization of graphite. In this section we focus our discussion on the formation mechanism of PAHs and fullerenes in sooting flamesa nd the interstellar medium (ISM).

\subsection{Proposed routes to PAHs in combustion systems and the ISM}

PAHs have been detected in flames and in soot samples ${ }^{[50]}$ and are a ubiquitous component of organic matter in space. Their presence in the ISM has been inferred from the diffuse interstellar band (DIB). ${ }^{\left[{ }^{11}\right]}$ Theoretical studies related to PAH formation in asymptotic giant branch (AGB) stars were performed by Frenklach and Feigelson, ${ }^{[52]}$ and by Cherchneff et al. ${ }^{[54]}$ These authors concluded that processes responsible for the formation of PAHs in AGB stars share similarities with terrestrial processes responsible for the formation of PAHs in sooting combustion flames. Numerous PAHs have also been identified in carbonaceous chondrite meteorites. For example, Becker and Bunch ${ }^{[54]}$ detected a variety of PAHs in the Allende meteorite. Among the numerous identified PAHs were compounds such as naphthalene, acenaphthylene, biphenyl, phenanthrene, fluoranthene, benzo(ghi)fluoranthene and corannulene. Let us note that the aforementioned PAHs have carbon skeletons of clusters that can be considered precursor intermediates in the growth sequences leading to the formation of $\mathrm{C}_{60}$ and $\mathrm{C}_{70}$ fullerenes. Numerous PAHs were also identified in the Murchison meteorite by De Vries et al. ${ }^{[5]}$, Callahan et al. ${ }^{[55]}$ and Joblin et al. ${ }^{[56]}$ Isotopic studies performed by Plows et al. ${ }^{[57]}$ convincingly support an interstellar origin of meteoritic PAHs.

Several models have been suggested for the formation mechanism(s) of PAHs in terrestrial and interstellar environments, but there is no general agreement among authors who champion these models. For more than three decades the hydrogen abstraction/acetylene addition (HACA) mechanism, which was proposed by Frenklach et al., ${ }^{[58]}$ has been considered the key route for the synthesis of PAHs, not only in sooting combustion flames, but also in outflows of carbon-rich AGB stars. ${ }^{[53]}$ The HACA route assumes a recurring sequence via abstractions of hydrogen atoms from the reacting aromatic hydrocarbon followed by consecutive addition of one or two acetylene molecule(s) before cyclization and aromatization. Interestingly, according to Mebel et al. ${ }^{[59]}$ one reason that the HACA route has often been labeled the most important route to PAH formation is because of the observed high abundance of acetylene in combustion systems that include various types of aliphatic and aromatic flames. Recently, the HACA mechanism has experienced a few drawbacks. Experimental and computational research has shown that the efficiency of the HACA mechanism is not enough to explain rapid growth of PAHs in flames. ${ }^{[60-61]}$ The study by Mebel et al. ${ }^{[59]}$ led to the conclusion that, both in combustion flames and in environmental mixtures, the HACA mechanism significantly underestimates the yield of PAHs containing only six-member rings, in particular the yield of phenanthrene, which exhibits an order of magnitude higher concentration than its isomer, anthracene. In the view of these authors, "this result points at the possible existence of another mechanism responsible for the formation of phenanthrene and other all- six-member ring PAHs." Doubts were raised about the ability of the HACA mechanism to reach the large mass of high-order PAHs such as coronene. ${ }^{\left[{ }^{60]}\right.}$ A recent experimental study by Parker et al. ${ }^{[62]}$ involving the reactions of naphthyl radicals with acetylene at combustion-like temperatures led them to doubt the validity of the HACA model. These reactions yielded 1- and 2-ethynylnaphthalenes, acenaphtylene and diethynylnaphthalenes. However, neither phenanthrene, nor anthracene was produced. Following this observation, the Parker team concluded that the absence of these tricyclic PAHs "is potentially representative of the inability of the HACA mechanism to be an effective route to ring formation for PAH formation beyond naphthalene." Due to the limitations of the HACA mechanism, several teams have offered alternative pathways for PAH formation. For instance, Skula et al. ${ }^{[63 \mathrm{a}-\mathrm{b}]}$ proposed a growth route to PAHs that they labeled the phenyl/addition cyclization (PAC) mechanism. This suggested process involves the addition of a phenyl radical at a fusing site of an aromatic species followed by dehydrocyclization $\left(-\mathrm{H}_{2}\right)$. The Skula team also proposed a mechanism for PAH growth that involves the reactions of methyl radicals with PAHs; they labeled this the methyl addition/ cyclization (MAC) mechanism. ${ }^{[63 c]}$ Other authors ${ }^{[64]}$ suggested that PAHs could form as the result of vinylacetylene addition to aromatic radicals.

So far, none of the aforementioned mechanisms seems to be able to adequately account for the formation of the large variety of PAHs in sooting combustion flames, or in the ISM. It is our view that the key reason for this is that those mechanisms all involve sequential additions of hydrogenated species such as acetylene, vinylacetylene, or the phenyl or methyl radicals to already hydrogenated aromatic compounds. Because they are already hydrogenated, in order to proceed, these processes require numerous steps that include hydrogen atom eliminations $(-\mathrm{H})$ and/or dehydrogenations $\left(-\mathrm{H}_{2}\right)$ and many of these steps necessitate high activation energy.

During processes occurring in combustions systems and the ISM, we do not exclude the possibility that some PAHs could form as the result of reactions involving hydrogenated species such as aromatic radicals. However, it is our view that the majority of the aromatic compounds do not originate as fully hydrogenated species. We propose the precursors of PAHs are most likely bare carbon clusters that could be produced as the result of cycloadditions involving $\mathrm{C}_{2}$ dimers, and the proposed cycloaddition processes would be similar to the growth processes that

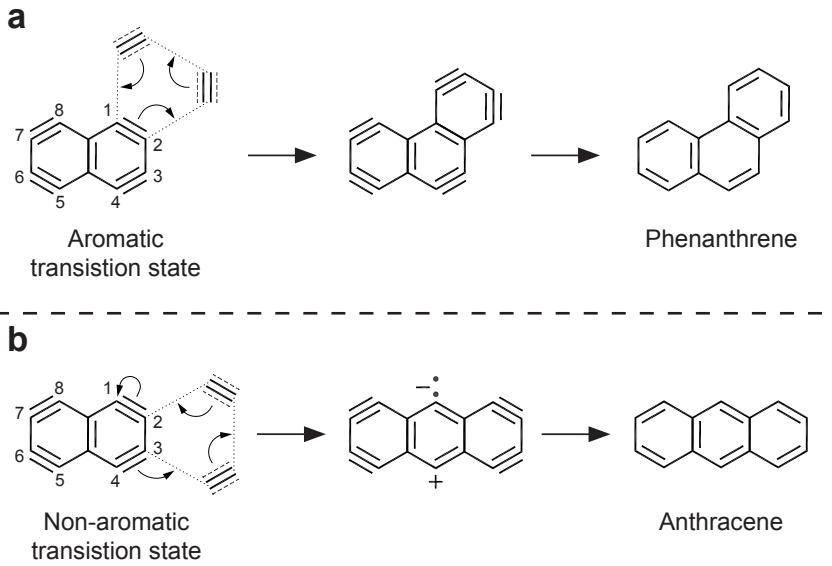

Scheme 10. It is proposed that one reason why, in combustion systems, phenanthrene is produced in higher abundance than anthracene is because its formation occurs via an aromatic transistion state as shown in a. 
were suggested in Section 9 where arc-discharge and laser vaporization methods were considered.

To substantiate our view that $\mathrm{C}_{2}$ dimers play a key role as growth species in flames and the ISM, let us note that $\mathrm{C}_{2}$ dimers have been detected in carbon-flames ${ }^{[12-15]}$ and in the ISM. ${ }^{[16-18]}$ In regard to our proposal that in the ISM the precursers of PAHs are dehydrogenated species, it is worth mentioning: 1) data from Duley and Lazarev ${ }^{[65]}$ showing evidence of the presence, in the ISM, of highly dehydrogenated PAH-like structure analogues to coronene, and; 2) studies by García-Hernández et al. ${ }^{[6]]}$ where they reported the possible detection, in a carbon-rich planetary nebulae, of the planar bare carbon cluster $\mathrm{C}_{24}$ that exhibits the carbon skeleton of coronene. It is interesting to note, that the possible detection of this $\mathrm{C}_{24}$ cluster by these authors was made in a region of space where they also identified the $\mathrm{C}_{60}$ and $\mathrm{C}_{70}$ fullerenes. ${ }^{[66]}$ To reiterate, it is our view that the formation of such highly dehydrogenated PAHs in the ISM are the result of cycloaddition processes involving of $\mathrm{C}_{2}$ dimers. This view significantly departs from the belief that dehydrogenated PAHs are produced from fully-hydrogenated PAHs that have lost their hydrogen atoms after being exposed to UV photons. ${ }^{[4 a-b, 65]}$

Let us return to the study by Mebel et al. ${ }^{[59]}$ in which they reported data showing that, in combustion flames and in environmental mixtures, the concentrations of phenanthrene are a factor 3-10 higher than the respective levels of anthracene. In the view of these authors, models such HACA could not explain this ratio.

To explain this observed high phenanthrene/anthracene ratio, let us consider the previously proposed growth sequences that could be responsible for the formation of the $\mathrm{C}_{14}(\mathrm{dPhe})$ and $\mathrm{C}_{14}(\mathrm{dAnt})$ clusters. As shown in Scheme10a, the cycloaddition reaction leading to the $\mathrm{C}_{14}(\mathrm{dPhe})$ involves one "triple bond" of the $\mathrm{C}_{10}(\mathrm{dNap})$ interacting with the two $\mathrm{C}_{2}$ dimers in such a way that it takes place via an energetically-favorable aromatic transition state. This creates a hexagonal ring that contains a stable sextet of $\pi$-electrons. By contrast, as shown in Scheme10b, the formation of the $\mathrm{C}_{14}(\mathrm{dAnt})$ cluster involves the interaction of two $\mathrm{C}_{2}$ dimers, one interacting with the $\mathrm{C} 1-\mathrm{C} 2$ "triple bond" and the other interacting with the $\mathrm{C} 3-\mathrm{C} 4$ "triple bond." These interactions are not as preferred as the one depicted in Scheme 10a because they don't take place via an energetically-favorable aromatic transition state. By comparing the two cycloaddition processes we get a better understanding as to why, in both combustion flames and environmental mixtures, phenanthrene, which is the hydrogenated form of $\mathrm{C}_{14}(\mathrm{dPhe})$, is produced in higher abundance than anthracene, which is hydrogenated form of $\mathrm{C}_{14}$ (dAnt). In addition to the reaction pathway shown in Scheme 10a, other routes could lead to the formation of the of $\mathrm{C} 14(\mathrm{dPhe})$ cluster. This would also contribute to the higher abundance of phenanthrene compared to anthracene. For example, the $\mathrm{C}_{14}(\mathrm{dPhe})$ cluster could form as the result of: 1$)$ a cycloaddition reaction involving the $\mathrm{C}_{6}(\mathrm{~dB})$ cluster that exhibits the carbon skeleton of benzene, and the $\mathrm{C}_{8}(\mathrm{dPAc})$ that exhibits the carbon of phenylacetylene, and; 2$)$ the addition of one $\mathrm{C}_{2}$ dimer to one bay region of the $\mathrm{C}_{12}(\mathrm{dbPhyl})$ that exhibits the carbon of biphenyl.

\subsection{Proposed routes to fullerenes in combustion systems}

It has been shown that fullerenes can form in low-pressure fuel-rich flames of hydrocarbons. ${ }^{[67]}$ It was observed that the highest yield was obtained under conditions of substantial soot formation and the most prevalent fullerenes produced in flames were $\mathrm{C}_{60}$ and $\mathrm{C}_{70}$. It was shown that these fullerenes form along with PAHs and soot. For example, in a 1998 experiment involving low-pressure premixed benzene/oxygen flames, Howards et al. ${ }^{[67 c]}$ identified thirty PAHs that include PAHs that exhibit the carbon skeletons of subunits of fullerenes, namely fluorene, fluoranthene, benzo[ghi]fluoranthene, benzo[b]-fluoranthene, benzo[k] fluoranthene, and corannulene. Also identified were large PAHs such as coronene and ovalene. Based on their observations that, under the conditions of combustion flames, fullerenes form along with PAHs, the Howard group offered the view that this gives some qualitative evidence for a link between $\mathrm{PAH}$ and fullerene formation. To explain how the $\mathrm{C}_{60}$ and $\mathrm{C}_{70}$ fullerenes could be produced in sooting combustion flames, Pope et al. ${ }^{[68]}$ suggested a mechanism involving the stepwise addition of acetylene $\left(\mathrm{C}_{2} \mathrm{H}_{2}\right)$ to hydrogenated fullerene fragments. They proposed that the route to $\mathrm{C}_{60}$ occurs via the following growth sequence: $\mathrm{C}_{16} \mathrm{H}_{10}$ (fluoranthene) $\rightarrow$ $\mathrm{C}_{20} \mathrm{H}_{10}$ (corannulene) $\rightarrow \mathrm{C}_{30} \mathrm{H}_{10}$ (pentacyclopentacorannulene) $\rightarrow \mathrm{C}_{40} \mathrm{H}_{10} \rightarrow$ $\mathrm{C}_{50} \mathrm{H}_{10} \rightarrow \mathrm{C}_{60}$. The route to $\mathrm{C}_{70}$ is assumed to take place via the sequence: $\mathrm{C}_{50} \mathrm{H}_{10} \rightarrow \mathrm{C}_{60} \mathrm{H}_{10} \rightarrow \mathrm{C}_{70}$. Because this mechanism involves addition of $\mathrm{C}_{2} \mathrm{H}_{2}$ to hydrogenated species as intermediates, it requires up to 75 steps that must take place in specific orders. These steps include multiple $\mathrm{H}$-abstractions, $\mathrm{C}_{2} \mathrm{H}_{2}$ additions, intramolecular rearrangements, and ring closures resulting from dehydrogenation processes. It is our view this very complex mechanism proposed by Pope's team does not adequately account for the formation of the $\mathrm{C}_{60}$ and $\mathrm{C}_{70}$ fullerenes in sooting flames.

We propose that in combustion systems, fullerenes most likely form as the result of growth sequences that involve sequential additions of $\mathrm{C}_{2}$ dimers to bare carbon clusters with these growth sequences being identical to those that we suggested in Sections 5 and 6 to explain the formation of $\mathrm{C}_{60}$ and $\mathrm{C}_{70}$ in laser vaporization and graphite arcs.

\subsection{Proposed routes to fullerenes in the ISM}

Fullerenes have been identified in various interstellar environments. The detection of $\mathrm{C}_{60}$ and $\mathrm{C}_{70}$ in a young planetary nebula was reported by Cami et al. ${ }^{[69]}$ and García-Hernández et al. ${ }^{[66]}$ The detection of $\mathrm{C}_{60}$ in a reflection nebula was reported by Sellgren et al. ${ }^{[70]}$ The presence of $\mathrm{C}_{60}{ }^{+}$has been recently confirmed in diffuse interstellar clouds. ${ }^{[1]}$ García-Hernández et al. presented evidence that that fullerenes and PAHs coexist in the circumstellar ejecta of low-excitation and H-containing planetary nebula in our galaxy and in the Small Magellanic Cloud. ${ }^{[72]}$ Based on Hubble Space Telescope data, combined with ground-based observations, in a 2019 report Cordiner et al. ${ }^{[73]}$ conclusively confirmed the presence of $\mathrm{C}_{60}{ }^{+}$in low-density, strongly-irradiated environments of interstellar space.

To explain how the $\mathrm{C}_{60}$ fullerene could form in the ISM, several "top-down" schemes have been proposed where larger carbon clusters shrink to reach $\mathrm{C}_{60}$. For example, Joblins et al. ${ }^{[4 a]}$ proposed that irradiation of the $\mathrm{C}_{66} \mathrm{H}_{20}$ PAH (circumovalene) could lead to the formation of $\mathrm{C}_{60}$. The chemical pathway suggested by these authors requires: 1) full dehydrogenation of $\mathrm{C}_{66} \mathrm{H}_{20} ; 2$ ) folding into a floppy closed cage, and; 3) shrinking of the cage by loss of three $\mathrm{C}_{2}$ units until it reaches the symmetric $\mathrm{C}_{60}$ molecule. Another important requirement is that $\mathrm{C}_{66} \mathrm{H}_{20}$ has to exist in significant abundance among a whole population of other small and large PAHs. A similar model was proposed by Zhen et al. ${ }^{[4 b]}$ where they suggested that $\mathrm{C}_{60}$ can form in the gas phase through irradiation of large PAHs such as $\mathrm{C}_{66} \mathrm{H}_{26}$. Chuvilin et al. ${ }^{[4 c]}$ proposed that $\mathrm{C}_{60}$ could form as the result of fast electron irradiation of graphene.

We propose that the $\mathrm{C}_{60}$ and $\mathrm{C}_{70}$ fullerenes that have been detected in the ISM could have been created along with PAHs as the result of the "bottom-up" mechanism that we have offered throughout this article. The processes leading to interstellar $\mathrm{C}_{60}$ and the $\mathrm{C}_{70}$ would involve, at the early stages, the creation of intermediates such as the $\mathrm{C}_{10}$ (dNap), $\mathrm{C}_{12}(\mathrm{dAcPy}), \mathrm{C}_{12}(\mathrm{dbPhyl}), \mathrm{C}_{14}(\mathrm{dPhe}), \mathrm{C}_{16}(\mathrm{dFlu}), \mathrm{C}_{18}(\mathrm{dBghiFlu})$ and $\mathrm{C}_{20}$ 
bowl clusters. Hydrogenations of these clusters would lead to the formation of naphthalene, acenaphthylene, biphenyl, phenanthrene, fluoranthene, benzo[ghi]fluoranthene, and corannulene, respectively. Let us point out that, as previously mentioned, these PAHs were identified in meteorites such as the Allende and Murchison. Also, as previously mentioned, isotopic studies performed by Plows et al. ${ }^{[57]}$ support an interstellar origin of these meteoritic PAHs.

\subsection{Soot Formation}

For many decades the mechanism of soot formation has been an active topic that remains a subject of debate among specialists working in the field of combustion research. ${ }^{[74]}$ It has been widely accepted by specialists that soot formation is a complex process during which PAHs are first formed, followed by particle nucleation (particle inception), coagulation, surface growth and oxidation. ${ }^{[75]}$ Many authors have indicated that the process of particle nucleation, which represents the transitions of gas-phase species to solid particles, is not well understood. For example, in 2011, Wang ${ }^{[76]}$ commented that the mechanism of soot nucleation remained elusive. As recently as 2018, Johansson et al. ${ }^{[77]}$ stated, "Notably, the identity of the chemical mechanism for soot and interstellar dust formation is a scientific puzzle." Also in 2018, Gross et al. ${ }^{[78]}$ said that "it is quite certain that the most complex, yet unresolved and scientifically intriguing phenomenon is the nucleation." The various models ${ }^{[77,79 \mathrm{a}-\mathrm{c}]}$ that have been proposed to explain the nucleation process involve the participation of radical intermediates such as cyclopentadienyl, phenyl, naphthyl and/or indenyl. However, let us point out that these radicals are supposed to form through $\mathrm{H}$ abstraction, a process that has a substantial energy barrier that forces the reactions rate to be too slow to account for the nucleation process that is known to take place in milliseconds. ${ }^{[75 a]}$ Also, the formation of these radicals would generally require the presence of $\mathrm{H}$ atoms to abstract the attached hydrogens from the PAHs. However, as Wang ${ }^{[76]}$ pointed out, it was shown that the mass growth of soot can proceed in the absence of gas-phase $\mathrm{H}$ atoms. This led him to state that it "leave[s] us with the notion that the soot nuclei may be formed through a mechanism which is not yet known."

To explain the soot nucleation process, we propose that the gaseous precursors present in the nucleation zone of sooting flames are actually dehydrogenated species, such as $\mathrm{C}_{2}$ dimers and bare carbon clusters, rather than acetylene molecules and PAHs. As we have suggested throughout this article, bare carbon clusters that exhibit the carbon skeleton of PAHs could be transformed into a variety of larger clusters by being involved in numerous of dimerization processes. These processes that could be responsible for the formation of dimers were discussed in Section 9. Interactions of newly formed dimers with other bare carbon clusters would lead to the formation of trimers, tetramers, and then to larger oligomers. During these interactions, oligomers could be linked to the ends of $\mathrm{C}_{2}$ dimers, or to the ends of linear clusters such as $\mathrm{C}_{4}, \mathrm{C}_{6}$, and $\mathrm{C}_{8}$. Note that this suggested process could account for the identification in soot material of aliphatic components existing in the form of alkyl, alkenyl side chains or cross linkages covalently bound to aromatic units. ${ }^{[80]}$ Interactions between newly created oligomers would lead to the formation of covalently bonded solid inception particles. Coagulation of these inception particles would result in the formation of larger aggregates and ultimately, to soot.

Let us point out that the just proposed soot formation mechanism involves interactions between bare carbon clusters. As such, this mechanism does not require processes with high-activation energy such as hydrogen abstraction reactions from PAHs. ${ }^{\left[{ }^{[1]}\right.}$ Consequently, the whole process could take place very quickly thus accounting for observations showing that the nucleation of soot takes place over milliseconds. ${ }^{[75 a]}$

What was proposed in this section can also explain why addition of molecular hydrogen $\left(\mathrm{H}_{2}\right)$ to a hydrocarbon fuel in diffusion flames has the effect of suppressing soot formation. ${ }^{[82]}$ According to our model, addition of $\mathrm{H}_{2}$ at the periphery of the bare carbon clusters that are produced during sooting flame processes would have several consequences: 1) it increases the yield of small PAHs; 2) it prevents the hydrogenated clusters from participating in further growth, thus reducing the yield of larger clusters, and; 3) it prevents these hydrogenated clusters from being involved in dimerization/oligomerization processes, which inhibits the formation of covalently bonded solid inception particles, and therefore reduces the formation of soot.

\section{Conclusions}

New insights were offered to explain how fullerenes and PAHs could form in carbon vapor, sooting flames, and in the ISM. We proposed that, under these different environments, fullerenes and PAHs are produced as the result of the same growth mechanism in which $\mathrm{C}_{2}$ dimers, rather than acetylene molecules, serve as building block units. In this "bottom-up" model, a series of detailed growth sequences were suggested to illustrate how [4+2] and $[2+2+2]$ cycloaddition processes involving $\mathrm{C}_{2}$ dimers could be responsible for the creation of bare carbon cluster intermediates of which the bowl shaped carbon clusters could serve as precursors for the formation of fullerenes. On the other hand, if hydrogenated, the bowl shaped and/or planar carbon clusters could give rise to a large variety of PAHs. We focused on the formation mechanism of the $I_{\mathrm{h}}-\mathrm{C}_{60}$ and $D_{5 \mathrm{~d}}-\mathrm{C}_{70}$ fullerenes, which have isolated pentagons. To explain why their pentagons are isolated, we suggested that they end up being nonadjacent merely as the consequence of always forming between hexagonal rings at the end of growth steps such as ring closure, "cove" closure, or cage closure. To account for fullerene isomerization, it was argued that the growth mechanism proposed in this article obviates the need to invoke the complex, yet widely used, Stone-Wales rearrangement. As an illustrative example to explain the formation of two $I_{\mathrm{h}}$-symmetry-breaking $\mathrm{C}_{60}$ isomers that contain fused pentagons, namely $C_{2 v}-\mathrm{C}_{60}$ and $C_{\mathrm{s}}-\mathrm{C}_{60}$, growth sequences were proposed that show how during the growth route to $I_{\mathrm{h}}-\mathrm{C}_{60}$, variations in the direction of just one or two reacting $\mathrm{C}_{2}$ dimers may be responsible for the creation of these two isomers. Furthermore, it was suggested that oligomerization of bare carbon clusters that form during growth processes involving $\mathrm{C}_{2}$ dimers could be responsible for the formation of soot particles.

The proposed model shows that fullerenes, PAHs, and soot can all form through simple steps that do not involve complex mechanisms with multitudes of transformations that would require high-activation energies.

We intend to apply our model to propose growth routes to higher fullerenes that contain isolated-pentagons, and to fullerenes having double- or triple-fused pentagons in their cage structures. A growth route to one typical example of fullerenes with adjacent pentagons, namely the "Saturn-shaped" $\mathrm{C}_{50} \mathrm{Cl}_{10}$ fullerene, was suggested in this article. We also intend to apply our model to gain a better understanding of the processes responsible for the formation of carbon nanotubes, as well as the creation of defects, such as for example, the heptagon-pentagon pair 5775 defect, that appear at the surface or edges of carbon nanotubes. In our view, such defects do not result from Stone-Wales transformations; they may originate, during cycloadditions processes, as the result of variations in the direction of interacting $\mathrm{C}_{2}$ dimers. 


\section{Acknowledgement}

The author thanks William M. Simon of Simconetics for his helpful discussions, significant contributions in drawing the figures and schemes, text editing, and his continuous great support and encouragement.

Keywords: $\mathrm{C}_{2}$ dimer $\bullet$ carbon cluster $\bullet \mathrm{C}_{60} \bullet \mathrm{PAH} \bullet$ fullerene

[1] H. W. Kroto, J. R. Heath, S. C. O'Brien, R. F. Curl, R. E. Smalley, Nature 1985, 318, 162-163.

[2] W. Krätschmer, K. Fostiropoulos, D. R. Huffman, Chem. Phys. Lett. 1990, 170, 167-170.

[3] a) H. W. Kroto, K. McKay, Nature 1988, 331, 328-331; b) J. R. Heath, ACS Symp. Ser. 1991, 481,1-23; c) S. Irle, G. Zheng, Z. Wang, K. Morokuma, J. Chem. Phys. B 2006, 110, 14531-14545; d) P. W. Dunk, N. K. Kaiser, C. L. Hendrickson, J. P. Quinn, C. P. Ewels, Y. Nakanishi, Y. Sasaki, H. Shinohara, A. G. Marshall, H. W. Kroto, Nat. Commun. 2012, 3, 855; e) J. S. Dang, W. W. Wang, J. J. Zheng, X. Zhao, E. Osawa, S. Nagase, J. Phys. Chem. C 2012, 116, 16233-16239; f) W. W. Wang, J. S. Dang, J. J. Zheng, X. Zhao, S. Nagase, J. Phys. Chem. C 2013, 117, 2349-2357.

[4] a) O. Berne, J. Montillaud, C. Joblin, Astron. Astrophys. 2015, 577, A133; b) J. Zhen, P. Castellanos, D. Paarderkooper, H. Linnartz, A. G. G. M. Tielens, ApJ. 2014, 797, L30; c) A. Chuvilin, U. Kaiser, E. Bichoutskaia, N. A.Besley, A.N. Khlobystov, Nat. Chem. 2010, 2, 450-453; d) J. Zhang, F. L. Bowles, D. W. Bearden, W. K. Ray, T. Fuhrer, Y. Ye, C. Dixon, K. Harich, R. F. Helm, M. M. Olmstead, A. L. Balch, H. C. Dorn, Nat. Chem. 2013, 5, 880-885.

[5] a) T.-M., Chang, A. Naim, S. N. Ahmed, G. Goodloe, P. B. Shelvin, J. Am. Chem. Soc. 1992, 114, 7603-7604; b) M. Zumwalt, Ph.D. Dissertation, University of Arizona, 1995; c) M. S. De Vries, K. Reihs, H. R. Wendt, W. G. Golden, H. E. Hunziker, R. Fleming, E. Peterson, S. Chang, Geochim. Cosmochim. Acta 1993, 57, 933938; d) M. Wilson, L. S. K. Pang, R. A. Quezada, K. J. Fisher, I. G. Dance, G. D. Willett, Carbon 1993, 31, 393-397; e) M. T. Beck, Z. Dinya, S. Kéki, L. Papp, Tetrahedron 1993, 49, 285-290.

[6] a) T. Grösser, A. Hirsch, Angew. Chem., Int. Ed. Engl. 1993, 32, 1340-1342; b) R.-B. Huang, S.-Y. Xie, Z.-C. Tang, Y.-H. Wang, W.-J. Huang, H. Chen, L.-S. Zheng, Journal of Cluster Science 1999, 10, 383-396; c) F. Gao, S.-Y. Xie, Z.-J. Mia, Y.-Q. Feng, R.B. Huang, L.-S. Zheng, Carbon 2004, 42, 1959-1963; d) S.-Y. Xie, S.-L. Deng, L.-J. Yu, R.-B. Huang, L.-S. Zheng, J. Chromatogr. A 2001, 932, 43-53; e) P. Fazekas, Z. Czégény, J. Mink, P. T. Szabó, A. M. Keszler, E. Bódis, S. Klébert, J. Szépvölgyi, Z. Károly, Plasma Chem. Plasma Process. 2018, 38, 771-790.

[7] a) S. Ahmad, K. Yasqub, A. Ashraf, Eur. Phys. J. D 2013, 67:51; b) M. Endo, H. W. Kroto, J. Phys. Chem. 1992, 96, 6941-6944; c) M. Mulet-Gas, L. Abella, P. W. Dunk, A. Rodriguez-Fortea, H. W. Kroto, J. M. Poblet, Chem. Sci. 2015, 6, 675-686.

[8] P. S. Skell, J. H. Plonka, J. Am. Chem. Soc. 1970, 92, 5620-5624.

[9] K. Uheda, K. Kuwahara, H. Fujiyama, Jpn. J. Appl. Phys. 1999, 38, 4512-4514.

[10] S. Ahmad, A. Quayyum, M. N. Akhtar, T. Riffat, Nucl. Instrum. Methods Phys. Res. B 2000, 171, 551-557.

[11] I. Labazan, N. Krstulović, S. Milošević, J. Phys. D; Appl. Phys. 2003, 36, 2465

[12] W. Swan, Trans. R. Soc. Edin. 1857, 21, 411-413.

[13] P. Bornhauser, G. Knopp, T. Gerber, P. P. Radi, J. Mol. Spectrosc. 2010, 262, 69-74.
[14] P. E. Bengtsson, M. Alden, Combustion and Flame 1990, 80, 322328.

[15] S. J. Harris, A, M. Weiner, Optic Lett. 1981, 6, 434-436.

[16] a) D. L. Lambert, A. C. Dansk, $A p J$ 1976, 268, 428-446; b) C. Laffont, P. Rousselot, J. Clairemidi, G. Moreels, Planet. Space Sci. 1998, 46, 585-601.

[17] a) A. C. Dansk, D. L. Lambert, Astron. Astrophys. 1983, 124, 188196; b) D. L. Lambert, Y. Sheffer, S. R. Federman, ApJ 1995, 438, 740-749; c) S. Iglesias-Groth, MNRAS 2011, 411, 1857-1862; d) D. E. Welty, J. C. Howk, N. Lehner, J. H. Black, MNRAS 2013, 428, 1107-1115

[18] J. W. Brault, L. Delbouille, N. Grevesse, G. Roland, A. J. Sauval, L. Testerman, Astron. Astrophys. 1982, 108, 201-205.

[19] N. Levine, Quantum Chemistry, 2nd edn, 321, table 13.2 (Allyn and Bacon, 1974).

[20] P. Su, J. Wu, J. Gu, W. Wu, S. Shaik, P. C. Hiberty, J. Chem. Theor. Comput. 2011, 7, 121-130;

[21] a) S.Shaik, D. Danovich, W. Wu, P. Su, H. S. Rzepa, P. C. Hiberty, Nat. Chem. 2012, 4, 195-200; b) S. Shaik, D. Danovich, B. Braida, P. C. Hibertry, Chem. Eur. J. 2016, 22, 4116-4128.

[22] G. Frenking, M. Hermann, Angew. Chem. Int. Ed. 2013, 52, 59225925.

[23] M. Hermann, G. Frenking, Chem. Eur. J. 2016, 22, 4100-4108.

[24] M. Endo, H. W. Kroto, J. Phys. Chem. 1992, 96, 6941-6944.

[25] M. Mulet-Gas, L. Abella, P. W. Dunk, A. Rodriguez-Fortea, H. W. Kroto, J. M. Poblet, Chem. Sci. 2015, 6, 675-686.

[26] R. Cruz-Silva, T. Araki, T. Hayashi, H. Terrones, M. Terrones, M. Endo, Phil. Trans. R. Soc. A 2016, 374, 20150327.

[27] M. Dresselhaus, G. Dresselhaus, P.Eklund, Science of Fullerenes and Carbon Nanotubes Academic Press, San Diego, CA, 1996.

[28] P. S. Skell, J. J. Havel, M. J. McGlinchey, Acc. Chem. Res. 1973, 6, 97-105.

[29] A. Van Order, R. J. Saykally, Chem. Rev. 1998, 98, 2313-2357.

[30] H. Massó, M. L. Senent, J. Phys. Chem. A 2009, 113, 12404-12410.

[31] G. Pascoli, A. Polleux, Astron. Astrophys. 2000, 359, 799-810.

[32] G. A. Adamson, C. W. Rees, J. Chem. Soc., Perkin Trans. 1 1995, 1535-1543.

[33] D. Peña, D. Pérez, E. Guitian, L. Castedo, J. Am. Chem. Soc. 1999, 121, 5827-5828.

[34] a) T. Hosoya, T. Hasegawa, Y. Kuriyama, K. Suzuki, Tetrahedron Lett. 1995, 36, 3377-3380; b) H. Yoshida, Y. Ito, Y. Yoshikawa, J. Ohshita, K. Takaki, Chem. Commun. 2011, 47, 8664-8666; c) R. W. Atkins, C. W. Rees, Chem. Commun. 1969, 4, 152; d) G. W. Gribble, D. J. Keavy, S. E. Branz, W. J. Kelly, M. A. Pals, Tetrahedron Lett. 1988, 48, 6227-6230; e) D. Niu, T. R. Hoye, Nat. Chem. 2014, 6, 34-40; f) D. Niu, P. H. Willoughby, B. P. Woods, B. Baire, T. R. Hoye, Nature 2013, 501, 531-534; g) P. H. Willoughby, D. Niu, T. Wang, M. K. Haj, C. J. Crame, T.R. Hoye, J. Am. Chem. Soc. 2014, 136, 13657-13665.

[35] C. W. Rees, R. C. Storr, Chem. Commun. 1965, 0, 193-194.

[36] H. W. Kroto, Nature 1987, 329, 529-531.

[37] T. G. Schmaltz, W. A. Seitz, D. J. Klein, Chem. Phys. Lett. 1986, 130, 203-207.

[38] S. Schein, T. Friedrich, Proc. Natl. Acad. Sci. USA 2008, 105, 19142-19147.

[39] M. S. Meier, G.-W. Wang, R. C. Haddon, C. Pratt Brock, M. A. Llyod, J. P. Selegue, J. Am. Chem. Soc. 1998, 120, 2337-2342.

[40] Y.-Z. Tan, Z.-J. Liao, Z.-Z. Qian, R.-T. Chen, X. Wu, H. Liang, X. Han, F. Zhu, S. J. Zhou, Z. Zheng, X. Lu, S.-Y. Xie, R.-B. Huang, L.-S. Zheng, Nat. Mater. 2008, 7, 790-794. 
[41] R. T. Chen, S. J. Zhou, H. Liang, Z.-Z. Qian, J.-M. Li, Q. He, L. Zhang, Y.-Z. Tan, X. Han, Z.-J. Liao, W.-Z. Weng, S.-Y. Xie, R.-B. Huang, L.-S. Zheng, J. Phys. Chem. C 2009, 113, 16901- 16905.

[42] S. J. Austin, P. W. Fowler, D. E. Manolopoulos, F. Zerbetto, Chem. Phys. Lett. 1995, 235, 146-151.

[43] A. J. Stone, D.J. Wales, Chem. Phys. Lett. 1986, 128, 501-503.

[44] a) P.A. Marcos, M. J. Lopez, A. Rubio, J. A. Alonso, Chem. Phys. Lett. 1997, 273, 367-370; b ) H. F. Bettinger, B. I. Yakobson, G. E. Scuseria, J. Am. Chem. Soc. 2003, 125, 5572-5580; c) W. I. Choi, G. Kim, S. Han, J. Ihm, Phys. Rev. B 2006, 73, 113406.

[45] L. T. Scott, Pure Appl. Chem. 1996, 68, 291-306.

[46] M. Sarobe, S. Flink, L. W. Jenneskens, J. W. Zwikker, J. Wesseling, J. Chem. Soc. Perkins Trans. 2 1996, 0, 2125-2131.

[47] S. Y. Xie, F. Gao, X. Lu, R. B. Huang, C. R. Wang, X. Zhang, M. L. Lius, S. L. Deng, L. S. Zheng, Science 2004, 304, 699.

[48] X. Han, S.-J. Zhou, Y.-Z. Tan, X. Wu, F. Gao, Z.-J. Liao, R. B. Huang, Y.-Q. Feng, X. Lu, S. Y. Xie, L. S. Zheng, Angew. Chem. Int. Ed. 2008, 47, 5340-5343.

[49] J.-H. Chen, Z.-Y. Gao, Q.-H. Weng, A.-S. Jiang, Q. He, H. Liang, L.-L. Deng, S.-L. Xie, H.-Y. Huang, X. Lu, S. Y. Xie, K. Shi, R. B. Huang, L. S. Zheng, Chem. Eur. J. 2012, 18, 3408-3415.

[50] a) K. Homann, Proc. Combust. Inst. 1985, 20, 857-870; b) R. A. Dobbins, R. A. Fletcher, H. C. Chang, Combust. Flame 1998, 115, 285-298; c) R. A. Dobbins, R. A. Fletcher, B. A. Benner Jr, S. Hooeft, Combust. Flame 2006,144, 773-781; d) B. Yang, Y. Li, L. Wei, C. Huang, J. Wang, Z. Tian, R. Yang, L. Sheng, Y. Zhang, F. Qi, Proc. Combust. Inst. 2007, 31, 555-563.

[51] A. G. G. M. Tielens, Annu. Rev. Astron. Astrophys. 2008, 46, 289337.

[52] M. Frenklach, E. D. Feigelson, ApJ 1989, 341, 372-384.

[53] I. Cherchneff, J. R. Barker, A. G. G. M. Tielens, ApJ 1992, 401, 269-287.

[54] L. Becker, T. E. Bunch, Meteorit. Planet. Sci. 1997, 32, 479-487.

[55] M. P. Callahan, A. Abo-Riziq, B. Crews, L.Grace, M. S. de Vries, Spectrochim. Acta Mol. Biomol. Spectrosc. 2008, 71, 1492-1495.

[56] H. Sabbah, A. Bonnamy, D. Papanastasiou, J.Cernicharo, J.-A. Martin-Gago, C. Joblin, ApJ 2017, 843: 34

[57] F. L. Plows, J. E. Elsilas, R. N. Zare, P. R. Buseck, Geochim. Cosmochim. Acta 2003, 67, 1429-1436.

[58] a) M. Frenklach, J. Warnatz, Combust. Sci. Technol.1987, 51, 265-283; b) H. Wang, M. Frenklach, Combust. Flame 1997, 110, 173-121; c) J. Appel, H. Bocckhorn, M. Frenklach, Combust. Flame 2000, 121, 122-136.; d) M. Frenklach, Phys. Chem. Chem. Phys. 2002, 4, 2028-2032.

[59] V. V. Kislov, A. I. Sadovnikov, A. M. Mebel, J. Phys. Chem. A 2013, 117, 4794-4816.

[60] H. Böhm, H. Jander, D. Tanke, Proc. Combust. Inst.1998, 27, 16051612.

[61] J. T. McKinnon, J. B. Howard, Proc. Combust. Inst.1992, 24, $965-$ 971.

[62] D.S. N. Parker, R. I. Kaiser, B. Bandyopadhyay, O. Kostko, T. P. Troy, M. Ahmed, Angew. Chem. Int. Ed. 2015, 54, 5421-5424.

[63] a) B. Shukla, M. Koshi, Combust. Flame 2011, 158, 369-375; b) B. Shukla, K. Tsuchiya, M. Koshi, J. Phys. Chem. A 2011, 115, 5824-5293; c) B. Shukla, A. Miyoshi, M. Koshi, J. Am. Chem. Mass Spectrom. 2010, 21, 534-544.

[64] a) D. S. N. Parker, F. Zhang, Y. S. Kim, R. I. Kaiser, A. Landera, V. V. Kislov, A. M. Mebel, A. G. G. M. Tielens, PNAS 2012, 109, 53-58; b) T. Yang, R. I. Kaiser, T. P. Troy, B. Xu, O. Kostko, M. Ahmed, A.. M. Mebel, M. V. Zagidullin, V. N. Azyazoy, Angew.
Chem. Int. Ed. 2017, 56, 4515-4519.

[65] W. W. Duley, S, Lazarev, ApJ 2004, 612, L33-L35.

[66] D. A, García-Hernández, S. Iglesias-Groth, J. A. Acosta-Pulido, A. Manchado, P. García-Lario, ApJ 2011, 737, L30.

[67] a) J. B. Howards, J. T. McKinnon, Y. Makarovsky, A. L. Lafleur, M. E. Johnson, Nature 1991, 352, 139-141; b) J. B. Howards, A. L. Lafleur, Y. Makarovsky, S. Mitra, C. J. Pope, T. K. Yadav, Carbon 1992, 30, 1183-1201; c) W. J. Grieco, A. L. Lafleur, K. C. Swallows, H. Richter, K. Taghizadeh, J. B. Howards, Proc. Combust. Inst. 1998, 27, 1669-1675.

[68] C. J. Pope, J. A. Marr, J. B. Howards, J. Phys. Chem. 1993, 97, 11001-11013.

[69] J. Cami, J. Barnard-Salas, E. Peeters, S. E. Malek, Science 2010, 329, 1180-1182.

[70] K.Sellgren, M. W. Werner, J. G. Ingalls, J. D. T. Smith, T. M. Carleton, C. Joblin, ApJ 2010,722, L54.

[71] E. K. Campbell, M. Holz, D. Gerlich, J. P. Maeir, Nature 2015, 523, 322-323.

[72] D. A, García-Hernández, A. Manchado, P.García-Lario, L. Stanghelleni, E, Villaver, R. A. Shaw, R. Shaw, R. Szczerba, J. V. Perea-Calderón, ApJ 2010, 724, L39-L43.

[73] M. A. Cordiner, H. Linnartz, N. L. J. Cox, J. Cami, F. Najarro, C.R. Proffitt, R. Lallement, P. Ehrenfreund, B. H. Foing, T. R. Gull, P. J. Sarre, S. B. Charmley, ApJL 2019, 875:L28

[74] a) J. S. Lowe, J. Y. W. Lai, P. Elvati, A. Violi, Proc. Combust. Inst. 2015, 35, 1827-1832; b) P. Desgroux, X. Mercier, K. A. Thomson, Proc. Combust. Inst. 2013, 34, 1713-1738.

[75] a) B. S. Haynes, H. G. Wagner, Prog. Energy Combust. Sci. 1981, 7, 229-273; b) H. F. Calcote, Combust. Flame 1981, 42, 215-242; c) K. H. Homann, Proc. Combust. Inst. 1985, 20, 857-870; d) H. Richter, J. B. Howards, Prog. Energy Combust. Sci. 2000, 26, 565-608.

[76] H. Wang, Proc. Combust. Inst. 2011, 33, 41-67.

[77] K. O. Johansonn, M. P. Head-Gordon, P. E. Schrader, K. R. Wilson, H. A. Michelsen, Science 2018, 361, 997-1000.

[78] F. Schultz, M. Commodo, K. Kaiser, G. De Falco, P. Minultolo, G. Meyer, A, D’ Anna, L. Gross, Proc. Combust. Inst. 2018, 000, 1-8.

[79] a) M. Frenklach, Phys. Chem. Chem. Phys. 2002, 4, 2028-2037; b) N. A. Slavinskaya, U. Riedel, S. B. Dworkin, M. J. Thomson, Combust. Flame 2012, 159, 979-995; c) Y. Wang, A. Raj. S. Huo Chung, Combust. Flame 2013, 160, 1667-1676.

[80] J. P. Cain, J. Camacho, D. J. Phares, H. Wang, A. Lakins, Proc. Combust. Inst. 2011, 33, 533-540.

[81] X. Ma, H. H. Schobert, Ind. Eng. Chem. Res. 2003, 42, 1151-1161.

[82] a) H. Guo, F. Liu, G. J. Smallwood, Ö. L. Gülder, Combust. Flame 2006, 145, 324-338; b) S.-H. Park, K.-M. Lee, C.-H. Hwang, Int. J. Hydrog. Energy 2011, 36, 9304-9311; c) S. De Iuliis, S. Maffi, F. Migliorini, F. Cignoli, G. Zizak, Appl. Phys. B 2012, 106, 707-715; d) H. Zhao, R. Stone, B. Williams, Energy Fuels 2014, 28, 21442151. 